\title{
Air Pollution and Criminal Activity: Microgeographic Evidence from Chicago
}

\author{
By Evan Herrnstadt, Anthony Heyes, Erich Muehlegger, \\ AND SOODEH SABERIAN*
}

\begin{abstract}
A growing literature documents that air pollution adversely impacts health, productivity, and cognition. This paper provides the first evidence of a causal link between air pollution and aggressive behavior, as documented by violent crime. Using the geolocation of crimes in Chicago from 2001-2012, we compare crime upwind and downwind of major highways on days when wind blows orthogonally to the road. Consistent with research linking pollution to aggression, we find that air pollution increases violent crime on the downwind sides of interstates. Our results suggest that pollution may reduce welfare and affect behavior through a wider set of channels than previously considered. (JEL K42, Q53)
\end{abstract}

\footnotetext{
ir pollution harms human well-being in a number of ways. Pollution has adverse effects on adult and infant health in the short and long run, ${ }_{1}^{\mathbb{1}}$ reduces productivity and labor market participation, ${ }^{2}$ impairs short-run cognition and lowers test scores, ${ }^{3}$ and induces avoidance behavior. ${ }^{4}$ This paper adds a new dimension to the literature on the adverse effects of pollution by providing quasi-experimental evidence that air pollution affects violent criminal activity, a behavior that is particularly costly from a societal perspective.

We study crime in the city of Chicago from 2001 to 2012. Our identification strategy exploits variation in pollution driven by daily changes in wind direction. We begin by illustrating the relationship between crime and pollution at the city

*Herrnstadt: US Congressional Budget Office (email: Evan.Herrnstadt@cbo.gov); Heyes: Department of Economics, University of Ottawa and University of Exeter (email: Anthony.Heyes@uottawa.ca); Muehlegger: Department of Economics, University of California-Davis and NBER (email: emuehlegger@ucdavis.edu); Saberian: Department of Economics, University of Manitoba (email: soodeh.saberian@umanitoba.ca). Ilyana Kuziemko was coeditor for this article. We thank William Greene, Pierre Brochu, Sophie Bernard, Doug Miller, Solomon Hsiang, Aureo de Paula, Rema Hanna, Paulina Oliva, Abel Brodeur, two referees from this journal, and seminar participants at Resources for the Future, UC-Berkeley, UC-Irvine, UC-Davis, the June 2016 Summer AERE meetings in Breckenridge, and the 2016 Royal Economic Society meetings at University of Sussex for very helpful comments. The views in this paper should not be interpreted as those of Congressional Budget Office. Remaining errors are ours.

Go to https://doi.org/10.1257/app.20190091 to visit the article page for additional materials and author disclosure statement(s) or to comment in the online discussion forum.

${ }^{1}$ Schlenker and Walker (2016), Currie and Walker (2011), Beatty and Shimshack (2014), among others.

${ }^{2}$ Hanna and Oliva (2015), Zivin and Neidell (2012).

${ }^{3}$ Lavy, Ebenstein, and Roth (2014); Stafford (2014); Archsmith, Heyes, and Saberian (2018).

${ }^{4}$ Ito and Zhang (2016), Moretti and Neidell (2011), Zivin and Neidell (2009).
} 
level, using wind direction as an instrument for pollution. Major industrial point sources, such as refineries, corn-milling facilities, and foundries, are located southeast and southwest of the city of Chicago. When the wind blows from those directions, ambient air pollution rises. Using wind direction as an instrument, we find that air pollution increases violent crime but not property crime, consistent with research from biology and medicine linking air pollution and aggression.

Although the city-level results provide suggestive evidence, credibly establishing a causal impact of pollution on crime faces several challenges. For example, existing research points to a relationship between weather (specifically temperature), aggression, conflict, and crime..$^{5}$ As pollution is both seasonal and a function of ambient weather conditions, misspecifying the relationship between weather and crime would risk misattributing the effect of temperature or other seasonal drivers of crime to ambient pollution.

To address this, we exploit the microgeography of pollution and crime in Chicago. Using the geocoordinates of the universe of two million serious crimes reported to the Chicago Police Department (CPD) between 2001 and 2012, we focus on the five major interstates that transect the city: I-90, I-94, I-290, I-55, and I-57. Following a literature that exploits interstates as a major fixed source of air pollution, $\rrbracket^{6}$ we estimate the causal effect of pollution on criminal activity by comparing crime on opposite sides of major interstates on days when the wind blows orthogonally to the direction of the interstate. As an example, I-290 runs due west from the Chicago city center to the suburbs of Oak Park and Berwyn. On days when the wind blows from the south, the pollution from the interstate impacts on the north side of the interstate, whereas when the wind blows from the north, the pollution impacts neighborhoods to the south. On days when the wind blows orthogonally to the interstate, we find that violent crime increases by 1.9 percent on the downwind side. The effects we find are unique to violent crimes-we find no effect of pollution on the commission of property crime.

In essence, this approach uses the upwind side of the interstate on a given day as a control for the "treated" downwind side on the same day. Because our analysis focuses on areas right next to particular interstates, the upwind and downwind neighborhoods likely face identical weather conditions and unobservable economic activity on a given day. This comparison helps us address the main threats to panel identification-omitted or misspecified variables correlated with both pollution and criminal activity - and is the major benefit of the microgeographic identification strategy that we adopt.

Our approach also allows for a set of supplementary empirical tests that support pollution as the mechanism. We find that the effect of being downwind is attenuated on days when the direction of the wind does not blow pollution exclusively to one side of the interstate. We also find that the marginal effect of being downwind declines with distance, consistent with the measurements of downwind pollution exposure from Karner, Eisinger, and Niemeier (2010). And, consistent with the hypotheses that the mechanism operates through contemporaneous exposure, we

\footnotetext{
${ }^{5}$ See, e.g., Hsiang, Meng, and Cane (2011) and Ranson (2014).

${ }^{6}$ See, e.g., Currie and Walker (2011) and Anderson (2020), among others.
} 
find evidence that (i) contemporaneous treatment rather than lagged treatment matters and (ii) the impacts of exposure are greatest on days with moderate temperatures when individuals are most likely to face outdoor exposure.

Finally, our localized analysis allows us to construct placebo tests based on 30 placebo "interstates" parallel to I-290. Estimating a treatment effect at each placebo interstate, we find that the downwind treatment estimate is maximized precisely at the latitude at which I-290 transects Chicago. Finally, we offer an alternative identification strategy that compares sides of the interstates to itself, on the same day of the year in other years in which location faced either more or less downwind exposure. Although the source of variation and control group is different than the identification strategy comparing the upwind and downwind sides on a given day (and our city-level results), we find very similar estimates of downwind exposure and continue to find an effect on violent, but not property, crime. The consistency of the city-level and interstate analyses lend credibility to the causal inference we draw from the evidence.

At this early point, it is useful to make explicit how this paper fits into the nascent literature linking short-term air pollution to crime. There are three papers most pertinent for us. Bondy, Roth, and Sager (2018) study crime in London. In their main specification, they apply fixed effect methods to a panel of data organized city-ward by day. They report a positive correlation between the air quality index (AQI) - a composite measure of air pollution based on multiple pollutants - in a ward on a given date and a range of both violent and nonviolent crimes. More concretely, a 10 percent increase in AQI is associated with a roughly 2 percent increase in overall crime. In a robustness exercise, they use wind-driven variation in local AQI levels to bolster causal interpretation of their main results. Burkhardt et al. (2019) apply similar fixed effects methods to a US county-by-day panel. They find that a 10 percent increase in fine particulates $\left(\mathrm{PM}_{2.5}\right)$ is associated with a 0.14 percent increase in violent crimes, and a 10 percent increase in ozone with a 0.3 percent increase. They find no relationship with nonviolent crime. Lu et al. (2018) examine a 9-year panel of air pollution and crime in 9,360 US cities. They estimate positive association between annual city-level violent and nonviolent crime and a composite city-level measure of air pollution. In each of these studies, the effect sizes on violent crime rates are similar in order of magnitude to those that we will develop. 7

Our paper has clear implications for policy. First, the effect sizes we estimate, although modest in magnitude, translate to significant social costs. Properly accounting for the impacts of pollution on criminal behavior would increase our estimates of the marginal external cost of air pollution and increase the optimal stringency of externality-correcting regulations or Pigouvian pollution taxes. Furthermore, our results suggest that air pollution might have much broader impacts on cognition and human behavior than previously considered, which would further increase the optimal Pigouvian tax on pollution. Finally, our work speaks to the growing literature

\footnotetext{
${ }^{7}$ Just as our analysis will identify effects of wind-borne pollution from roads in the aggregate, these studies are also best interpreted as exploring portmanteau pollution effects. Lu et al. (2018) and Bondy, Roth, and Sager (2018) are both explicit in using a composite pollution metric, and while Burkhardt et al. (2019) include as regressors $\mathrm{PM}_{25}$ and ozone they do not report results for other common pollutants, such as nitrogen oxides (NOx), carbon monoxide $(\mathrm{CO})$, and particles of other sizes, often highly correlated with those that they study.
} 
documenting the importance of within-city variation in pollution on specific neighborhoods. In recent years, concerns about local variation in pollution exposure have resonated with policymakers - much of state and local policy related to "environmental justice" is motivated by a desire to address differential pollution exposure faced by particular demographic groups.

The road map for the rest of the paper is as follows. In Section I, we summarize the existing literature in biology, medicine, and psychology linking air pollution to aggressive behavior. Although this paper documents a causal effect of air pollution on violent crime, previous research highlights several possible channels that-individually or in combination - might underpin the causal relationship we estimate. We discuss data in Section II and in Section III provide suggestive city-level evidence. In Section IV, we examine the microgeography of criminal activity in Chicago proximate to major interstates. Section V discusses policy implications, and Section VI concludes.

\section{Research on Environmental Conditions and Aggression}

There is a long history in criminology, sociology, and economics focused on the relationship between criminal activity and environmental conditions. The relationship between ambient temperature and crime is well documented. Ranson (2014) uses 50 years of monthly data across nearly 3,000 US counties to semiparametrically estimate a flexible relationship between crime and weather. He finds that violent crime increases approximately linearly with respect to ambient temperature. ${ }^{8}$ Similar patterns arise when considering aggressive behavior at levels from the interpersonal to the societal and in countries around the world (Burke et al. 2009; Hsiang, Meng, and Cane 2011; Hsiang, Burke, and Miguel 2013). Other documented environmental drivers of crime include rainfall, most commonly by impacting agricultural productivity (Iyer and Topalova 2014) and ambient light (Doleac and Sanders 2015).

In addition to the three recent papers outlined above, an older literature provides correlational evidence of association between short-run air pollution and interpersonal conflicts and adverse psychological outcomes. Rotton and Frey (1985) find that higher ozone levels in Dayton, Ohio, are related to increased domestic disturbance calls and assaults, though the latter is not statistically significant. Research has also documented a positive correlation between air pollution and adverse psychological outcomes. Rotton and Frey (1984) use data on psychiatric emergencies from the Dayton Police Department and find that such calls are positively correlated with levels of ozone precursors and sulfur dioxide, even when controlling for time trends and contemporaneous weather conditions. Szyszkowicz (2007) documents a similar positive correlation between emergency department visits for depression and ambient levels of a variety of pollutants, including $\mathrm{CO}$, nitrogen dioxide $\left(\mathrm{NO}_{2}\right)$, sulfur dioxide $\left(\mathrm{SO}_{2}\right)$, ozone, and $\mathrm{PM}_{2.5}$. Further, there are several studies that find a positive association between levels of air pollution pollutants and suicide, suicide

\footnotetext{
${ }^{8}$ Cohn and Rotton (1997) and Jacob, Lefgren, and Moretti (2007) provide similar evidence that violent crime increases with temperature and decreases with precipitation.
} 
attempts, and suicidal ideation as well as psychiatric admission rates (Lim et al. 2012; Szyszkowicz et al. 2010; Yang, Tsai, and Huang 2011; Briere, Downes, and Spensley 1983; Strahilevitz, Strahilevitz, and Miller 1979). To our knowledge, there are no studies focusing on long-run exposure to air pollution, although Reyes (2007) exploits the staggered phaseout of leaded gasoline in the United States and finds that childhood lead exposure increases a cohort's future crime rate.

In this paper, we remain agnostic on the underlying mechanism (or mechanisms). However, previous research in medicine, biology, and psychology identifies several pathways by which pollution exposure might affect aggression. The first, and perhaps most straightforward, is that pollution might manifest in physical discomfort. I $^{9}$ A long literature in psychology summarized by Anderson and Bushman (2002) documents a link between physical discomfort and aggressive behavior. Most relevant to our work, Rotton (1983) and Rotton et al. (1978) found laboratory exposure to malodorous reduced subjects' cognitive performance, tolerance for frustration, and ratings of other people and the physical environment. ${ }^{10} \mathrm{~A}$ second documented pathway linking pollution and aggression is that air pollution may directly affect brain chemistry by lowering levels of serotonin. Serotonin is a neurotransmitter that acts an a inhibitor. Low levels of serotonin are associated with increased aggression and impulsivity in adults, children, and animals. ${ }^{\Pi 1}$ Krueger, Andriese, and Kotaka (1963); Paz and Huitrón-Reséndiz (1996); González-Guevara et al. (2014); and Murphy et al. (2013) provide observational and experimental evidence linking short-term pollution exposure (specifically ozone) to decreased serotonin in animals. Third, Levesque et al. (2011) and Van Berlo et al. (2010) find that air pollutants can inflame nerve tissues in humans, dogs, mice, and rats. Rammal et al. (2008) finds experimental evidence that oxidative stress and similar neuroinflammation increases aggression in mice, specifically the frequency with which mice attack unfamiliar mice put into their space. Finally, pollution may lead to other physiological changes that manifest in increased aggression. Maney and Goodson (2011) survey the literature on the role played by hormonal mechanisms in animal aggression. Uboh et al. (2007) provide experimental evidence causally linking exposure to gasoline vapors to substantially elevated levels of testosterone in male rats. Testosterone is itself linked to violent crime in humans (Dabbs Jr. et al. 1995, Birger et al. 2003).12

\footnotetext{
${ }^{9}$ Ambient air pollution exposure is known to manifest in physical discomfort. For instance, Nattero and Enrico (1996) followed 32 subjects over the span of 9 months and found that high concentrations of ambient $\mathrm{CO}$ and $\mathrm{NO}_{x}$ were both significantly correlated with incidence of headache.

${ }^{10}$ Physical discomfort is also a central hypothesized mechanism for the link between high temperatures and aggression in both the laboratory (Baron and Bell 1976) and the field (Ranson 2014).

${ }^{11}$ Coccaro et al. (2011) summarizes the literature linking serotonin depletion and impluse control. Decreased serotonin is associated with an increased tendency to fight among rhesus monkeys (Faustman, Ringo, and Faull 1993), increased impulsive aggression in children (Frankle et al. 2005), and decreased harm avoidance in adults (Hansenne et al. 1999). In an experimental study, Crockett et al. $(2013,3505)$ find that "(serotonin) depleted participants were more likely to punish those who treated them unfairly, and were slower to accept fair exchanges." In their summary of the human subject literature, Siegel and Crockett $(2013,42)$ note that "a meta-analysis encompassing 175 independent samples and over 6,500 total participants reveals a reliable inverse relationship between serotonin and aggression."

${ }^{12}$ As another example, CO may directly affect physical and cognitive functioning by binding to hemoglobin and reducing the oxygen-carrying capacity of the cardiovascular system. This oxygen deficiency can have deleterious effects on an exposed individual. In a rare controlled experiment, Amitai et al. (1998) exposed 45 Hebrew University students to various levels of $\mathrm{CO}$ and found that low-level exposure impaired learning, hindered attention and concentration, and slowed visual processing.
} 


\section{Data}

Our crime data come from administrative records documenting all crimes reported to the CPD between 2001 and 2012. We obtain crime data from the CPD's Citizen Law Enforcement Analysis and Reporting system, accessed using the city of Chicago's open data portal (CPD 2001-2012). For each reported crime, the dataset reports the type of crime; the date, time of day, latitude, and longitude of the address at which the crime was reported; and other details of the incident (e.g., whether an arrest was made, whether the crime was considered domestic).

To narrow our focus to commonly examined crimes, we restrict the sample to the two million FBI Type I crimes reported in the city of Chicago between 2001 and 2012, including homicide, forcible rape, robbery, assault, battery, burglary, larceny, arson, and grand theft auto. As some types of serious crime are infrequent, we aggregate these crimes into violent crimes (homicide, forcible rape, assault and battery) and property crimes (burglary, robbery, larceny, arson, and grand theft auto). The 240,000 violent crimes are predominately battery (57 percent) and assault (32 percent), while the 1.8 million property crimes are predominately larceny ( 58 percent), burglary (17 percent), and grand theft auto (14 percent). ${ }^{13}$

As in many locations, crime in Chicago declined over the 2001-2012 study period and exhibits substantial seasonality and within-day variation. We document these patterns in the online Appendix. ${ }^{14}$ The time stamp of each crime reflects the time at which the crime was reported rather than committed. This might result in some degree of misreporting in terms of the hour (more likely) or the date (less likely). Consequently, we focus on daily variation in crime and pollution and aggregate crimes to the daily level.

The geographic patterns of property versus violent crime also differ. The heat maps in online Appendix Figure A.4 plot the density of property and violent crime throughout Chicago for 2001-2012. The grey lines denote the major interstates running through the city limits. The shades are comparable only within a map; that is, an area on the violent crime map that is darker than an area on the property crime map does not necessarily indicate that there are more violent crimes there in absolute terms. Rather, the share of violent crimes that occur in that area is greater than the share of property crimes. Less affluent locations such as the South Side and the westernmost portions of Chicago experience higher rates of violent crime. Although these areas also experience high rates of property crime, downtown Chicago experiences higher rates of property crime.

The temporal, seasonal, and geographic distributions of crime nicely summarize some of the identification challenges that we face. First, crime and pollution have both been declining over time in Chicago. Thus, we focus on short-run variation

\footnotetext{
${ }^{13}$ We only observe crimes reported to the CPD. Crimes may be differentially underreported, especially those that are personally sensitive. However, unless underreporting is correlated with wind-driven pollution levels, underreporting will not bias our estimates.

${ }^{14}$ Online Appendix Figure A.3 presents the annual trends in property and violent crimes between 2001 and 2012. Each type of crime's 2001 level is normalized to 100 . Overall, violent crime has declined more rapidly than property crime, although both varieties are far below their 2001 levels. Figure A.2 plots the seasonality of crime in Chicago - both violent crime and property crime increase during the summer months. Criminal activity also cycles over the course of each day-Figure A.1 shows that crime peaks during evening hours.
} 


\begin{tabular}{lcc}
\hline \hline & Mean & $\begin{array}{c}\text { Standard } \\
\text { deviation }\end{array}$ \\
\hline Citywide sample: & & \\
Number of dates & 3,642 & \\
Daily citywide violent crime & 57.4 & 18.7 \\
Daily citywide property crime & 420.1 & 68.4 \\
Precipitation $(\mathrm{mm})$ & 2.75 & 7.74 \\
Maximum temperature $\left({ }^{\circ} \mathrm{C}\right)$ & 15.5 & 11.6 \\
Daily average $\mathrm{CO}(\mathrm{ppm})$ & 0.59 & 0.27 \\
Daily average $\mathrm{NO}_{2}(\mathrm{ppm})$ & 0.027 & 0.0084 \\
Daily average ozone $(\mathrm{ppm})$ & 0.023 & 0.012 \\
Daily average $\mathrm{PM}_{10}\left(\mu \mathrm{g} / \mathrm{m}^{3}\right)$ & 27.7 & 14.4 \\
Wind speed $(\mathrm{km} / \mathrm{h})$ & 12.3 & 4.40 \\
Dew point $\left({ }^{\circ} \mathrm{C}\right)$ & 4.44 & 10.1 \\
Air pressure $(\mathrm{hpa})$ & $1,016.6$ & 7.09 \\
Cloud cover sunrise to sunset $($ percent $)$ & 63.8 & 27.7 \\
& & \\
Interstate sample: & & \\
Interstate-side days & 41,730 & 1.4 \\
Daily interstate-side violent crimes & 1.1 & 5.2 \\
Daily interstate-side property crimes & 7.3 & \\
\hline
\end{tabular}

for causal identification. Second, seasonality of pollution and crime suggests that weather (particularly temperature) is an important confounding variable. Third, geographic variation in crime stresses the importance of an identification strategy to address unobservable economic activity.

To control for weather conditions, we use data downloaded from the National Climatic Data Center (NCDC) Integrated Surface Database (NCDC 2001-2012)..$^{15}$ The Integrated Surface Database is the most comprehensive source of publicly available US weather data, reporting temperature, precipitation, and other meteorologic variables at approximately 10,000 locations. For the analysis, we use temperature, precipitation, wind speed, and wind direction at Midway Airport, the weather station to the Chicago city center consistently reporting all four variables. ${ }^{16}$ As we are aggregating our crime data to the daily level, we construct a measure of the average wind vector over the course of a day from hourly data. We construct similar summary statistics for available covariates correlated with crime, such as daily maximum temperature and precipitation. Table 1 presents the means and standard deviations of our relevant empirical variables.

\section{City-Level Crime and Pollution}

We start by establishing a suggestive relationship between pollution and crime at the city level using a time series variation. In Chicago, day-to-day variation in is

\footnotetext{
${ }^{15}$ Comprehensive data from the Integrated Surface Database can be downloaded via FTP at ftp://ftp.ncdc.noaa. gov/pub/data/noaa/. The subset of the data relevant for this analysis is provided as part of the data archive.

${ }^{16}$ As a comparison, we also examined similar variables at O'Hare, located approximately twice as far from the city center as Midway Airport. Readings at Midway and O'Hare for all four variables are highly correlated. Correlation in temperatures, precipitation, wind speed, and wind direction were $0.995,0.750,0.950$, and 0.703. Our results throughout the paper are not sensitive to the choice of weather station.
} 
partially driven by major industrial point sources located to the southwest and southeast of Chicago, including the Blue Island refinery and Arcelor Mittal steel mill to the southeast and the ExxonMobil Joliet refinery, the Citgo Lemont refinery, and the Corn Products International wet-corn-milling operation to the southwest. Due to the coverage of monitors in Chicago over the study period, we focus on $\mathrm{PM}_{10}$ readings, recognizing that $\mathrm{PM}_{10}$ emissions act as a proxy for many industrial pollutants. ${ }^{17} \mathrm{As}$ an illustration of our identification strategy, Figure 1 plots the relationship between wind speed, wind direction, and pollution at a specific $\mathrm{PM}_{10}$ monitor in Chicago..$^{18}$ The shade of the plot region represents mean pollution intensity, the arc direction represents the average direction from which the wind is blowing, and the distance from the center of the circle represents vector-based wind speed. As the figure illustrates, when winds originate from either the southeast or southwest, the monitor reports elevated $\mathrm{PM}_{10}$ levels. In contrast, when the wind originates from the direction of Lake Michigan, $\mathrm{PM}_{10}$ concentrations are lower.

Our empirical strategy is relatively straightforward. To address seasonality and disparities between the weekdays and weekends, we include a set of calendar fixed effects, including month-of-year fixed effects, day-of-week fixed effects and dummy variables corresponding to holidays and the first day of each month. To address the correlation of both pollution and crime with weather conditions, we flexibly condition on temperature and precipitation using a semiparametric bin estimator for both and include other weather observables (e.g., sky cover, dew point, and barometric pressure). Finally, to address unobservable economic activity, we instrument for pollution using wind direction, exploiting the fact that when winds originate from the southeast or southwest, monitors in Chicago report elevated pollution levels. In this case, the identification strategy is similar in spirit to that of Schlenker and Walker (2016), who use wind direction and airport emissions to instrument for ambient pollution in California to estimate causal health effects. Hence, the relevant exclusion restriction is that there are no omitted variables correlated with both crime and wind direction after conditioning on fixed effects and weather covariates. As an example, this might be violated if after conditioning on weather and fixed effects, winds off of Lake Michigan affected people's moods in a way that lowered violent crime. In this case, we might misattribute a "Lake Michigan" effect on crime to pollution.

Formally, we estimate the following 2SLS specification:

$$
\begin{aligned}
\text { Poll }_{t} & =\alpha W_{t}+\beta X_{t}+\epsilon_{t}, \\
\ln \left(\text { Crime }_{t}\right) & =\gamma X_{t}+\lambda \widehat{\text { Poll }_{t}}+\nu_{t} .
\end{aligned}
$$

The variable $W_{t}$ includes daily average wind direction in 20-degree bins; $X_{t}$ is a vector of controls including $5^{\circ} \mathrm{C}$ daily maximum temperature bins, daily precipitation, vector-based average wind speed, binned dew point, barometric pressure and

\footnotetext{
${ }^{17}$ Our direct measures of ambient pollution come from the Environmental Protection Agency's (EPA) network of monitors. We use 24-hour averages provided by the EPA. To avoid composition problems, we only include days for which all the $\mathrm{PM}_{10}$ monitors have a valid daily average.

${ }^{18}$ For reference, monitor $31-1016-3$ is located in the city limits, approximately 12 miles southeast of the city center.
} 


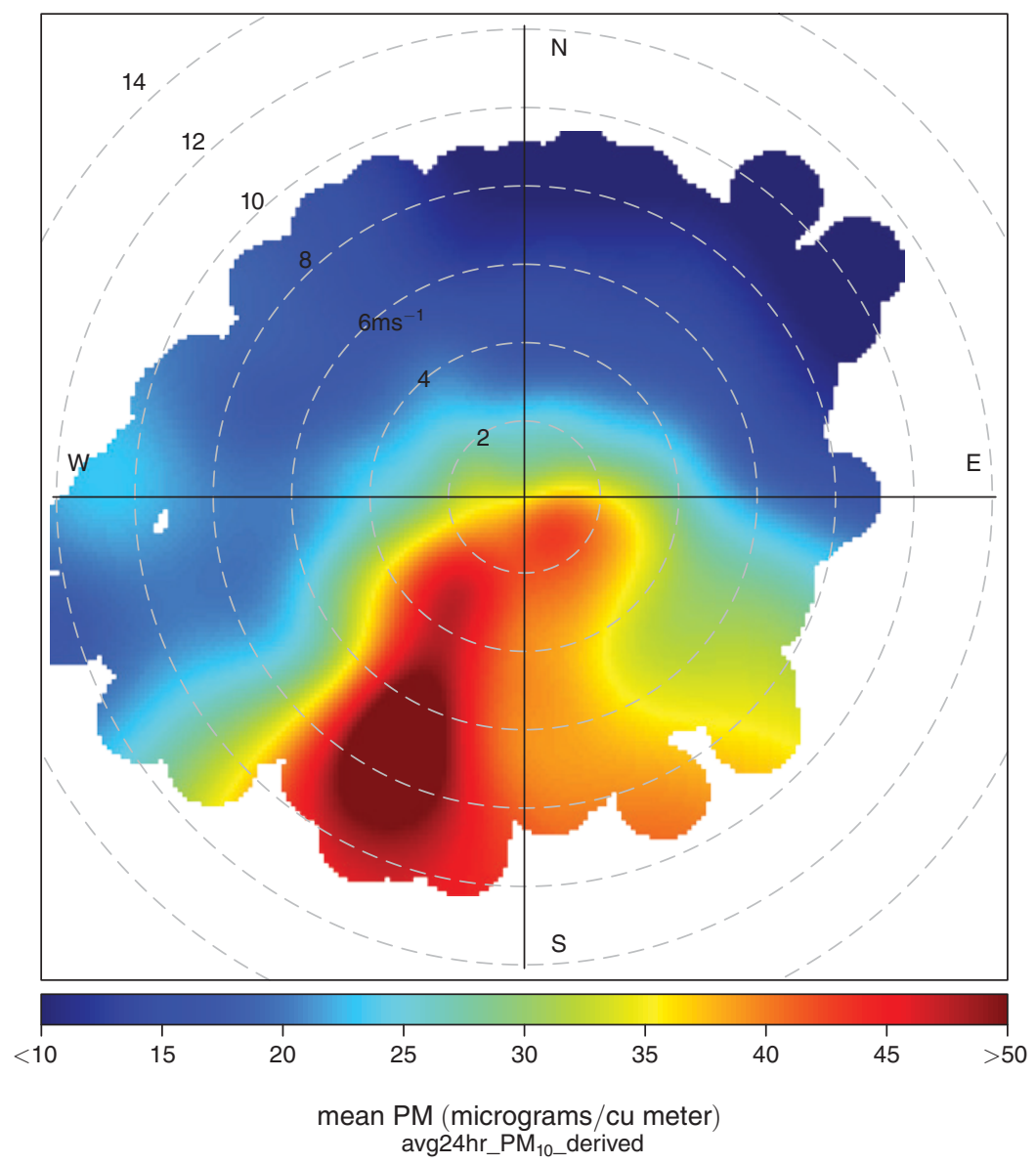

Figure 1. Average PM 10 Reading by Wind Direction and Vector-Based Speed

Notes: Shading denotes mean hourly $\mathrm{PM}_{10}$ readings over sample period at Monitor 31-1016-3. The vector from the origin to a particular point denotes the direction from which wind is blowing, and the distance from the origin denotes average wind speed (in meters/second). For example, the point $(0,2)$ reflects average emissions in an hour during which the wind is blowing from the east at 2 meters per second.

average sky cover, and a set of calendar fixed effects, including a first-of-month indicator, a January 1 indicator, holiday indicators, day-of-week dummies, and monthof-sample dummies. The set of controls also includes the average maximum daily temperature over 1991-2000 matched by day of year to the study sample as an additional control for seasonal variation in temperature. ${ }^{19}$ The term Poll $_{t}$ is the average daily $\mathrm{PM}_{10}$ across all $\mathrm{PM}_{10}$ monitors in the city of Chicago, standardized so that a unit change in the variable is equal to a 1 standard deviation increase $\left(14.4 \mu \mathrm{g} / \mathrm{m}^{3}\right)$. Our dependent variable Crime $_{t}$ is the log of the total number of violent or property crimes in Chicago on day $t$. To allow for serial correlation in weather and criminal activity, we report Newey-West standard errors in all specifications. 
Table 2-PM 10 Impact on Daily Part 1 Crime, 2001-2012

\begin{tabular}{|c|c|c|c|c|c|c|}
\hline & \multicolumn{3}{|c|}{ Violent crimes } & \multicolumn{3}{|c|}{ Property crimes } \\
\hline & OLS & OLS & IV & OLS & OLS & IV \\
\hline & (1) & (2) & (3) & (4) & $(5)$ & (6) \\
\hline $\begin{array}{l}\text { Standardized } \\
\mathrm{PM}_{10} \text { reading }\end{array}$ & $\begin{array}{c}0.061 \\
(0.0037)\end{array}$ & $\begin{array}{c}0.014 \\
(0.0043)\end{array}$ & $\begin{array}{c}0.029 \\
(0.013)\end{array}$ & $\begin{array}{c}0.0041 \\
(0.0014)\end{array}$ & $\begin{array}{l}-0.0013 \\
(0.0019)\end{array}$ & $\begin{array}{c}0.0013 \\
(0.0058)\end{array}$ \\
\hline First-stage $F$-statistic & & & 26.4 & & & 26.4 \\
\hline Calendar fixed effects & $\mathrm{X}$ & $\mathrm{X}$ & $\mathrm{X}$ & $\mathrm{X}$ & $\mathrm{X}$ & $\mathrm{X}$ \\
\hline Weather controls & & $\mathrm{X}$ & $\mathrm{X}$ & & $\mathrm{X}$ & $\mathrm{X}$ \\
\hline Historical mean temp & & $\mathrm{X}$ & $\mathrm{X}$ & & $\mathrm{X}$ & $\mathrm{X}$ \\
\hline Observations & 3,642 & 3,642 & 3,642 & 3,642 & 3,642 & 3,642 \\
\hline$R^{2}$ & 0.69 & 0.75 & 0.75 & 0.79 & 0.81 & 0.81 \\
\hline
\end{tabular}

Notes: Newey-West robust standard errors reported. Dependent variable is the log of the daily number of violent crimes (columns 1-3) and log of the daily number of property crimes (columns 4-6). Calendar fixed effects include year-month fixed effects, day of week fixed effects, and first-of-month, first-of-year, and holiday dummies. Weather variables include binned maximum daily temperature, binned dew point, precipitation, barometric pressure, and average sky cover. Historical mean temperature is the average maximum temperature over 1991-2000 matched by day of year to the study period. Excluded instruments are 20 degree bins for daily average wind direction at Midway Airport. The pollution variable of interest is the standardized mean reading over monitors 31-22-3 and 31-1016-3.

Table 2 displays the results from the city-level regressions. Columns 1 through 3 present the results using violent crimes as the dependent variable. Column 1 presents the results from an OLS regression of violent crime on pollution and calendar fixed effects. Column 2 adds weather controls and historical mean temperature matched by day of year. Column 3 presents the IV estimates, using wind direction as a first-stage excluded instrument for pollution. As suggested by Figure 1, the first stage is quite strong-the $F$-statistic is 26.4 .

Column 1 highlights one of the identification challenges we face with estimating an effect of pollution on crime, specifically the strong correlation among weather, pollution, and criminal activity. Including calendar fixed effects but not weather controls, we estimate that a 1 standard deviation increase in $\mathrm{PM}_{10}$ emissions is associated with a 6 percent increase in violent crime. But, the estimate conflates a potential effect of pollution with the effect of weather. $\mathrm{PM}_{10}$ pollution and temperature are positively correlated, as are temperature and criminal activity. Adding flexible weather covariates in column 2 reduces the coefficient on $\mathrm{PM}_{10}$ pollution by roughly 80 percent. Column 3 presents the 1s, using binned wind direction as a first-stage instrument. Using this specification, we estimate that a 1 standard deviation increase in $\mathrm{PM}_{10}$ emissions is associated with a 2.9 percent increase in violent crime. As a point of reference, the estimated effect of moving from the $77-86^{\circ} \mathrm{F} / 25-30^{\circ} \mathrm{C}$ maximum temperature bin to the $86-95^{\circ} \mathrm{F} / 30-35^{\circ} \mathrm{C}$ bin is a 7 percent increase in violent crime. 20

\footnotetext{
${ }^{20}$ Again, a bit of cautious interpretation of our estimate is necessary. As we note above, $\mathrm{PM}_{10}$ readings are an observable proxy for industrial air pollution that is likely a mix of a air pollutants. We have also run specifications that expressly condition on copollutants and find qualitatively similar results.
} 
Table 3-PM 10 Impact on Daily Part 1 and Non-Part 1 Crime, 2001-2012

\begin{tabular}{|c|c|c|c|c|c|c|}
\hline & \multicolumn{3}{|c|}{ Violent } & \multicolumn{3}{|c|}{ Nonviolent } \\
\hline & $\begin{array}{c}\text { FBI Part } 1 \\
\text { (1) }\end{array}$ & $\begin{array}{c}\text { Non-Part } 1 \\
\text { (2) }\end{array}$ & $\begin{array}{l}\text { All } \\
(3)\end{array}$ & $\begin{array}{c}\text { FBI Part } 1 \\
\text { (4) }\end{array}$ & $\begin{array}{c}\text { Non-Part } 1 \\
(5)\end{array}$ & $\begin{array}{l}\text { All } \\
(6)\end{array}$ \\
\hline Standardized $\mathrm{PM}_{10}$ reading & $\begin{array}{c}0.029 \\
(0.013)\end{array}$ & $\begin{array}{c}0.014 \\
(0.0080)\end{array}$ & $\begin{array}{c}0.017 \\
(0.0076)\end{array}$ & $\begin{array}{c}0.0013 \\
(0.0058)\end{array}$ & $\begin{array}{c}0.0091 \\
(0.0070)\end{array}$ & $\begin{array}{c}0.0055 \\
(0.0053)\end{array}$ \\
\hline Calendar fixed effects & $\mathrm{X}$ & $\mathrm{X}$ & $\mathrm{X}$ & $\mathrm{X}$ & $\mathrm{X}$ & $\mathrm{X}$ \\
\hline Weather controls & $\mathrm{X}$ & $\mathrm{X}$ & $X$ & $X$ & $\mathrm{X}$ & $\mathrm{X}$ \\
\hline Historical mean temperature & $\mathrm{X}$ & $\mathrm{X}$ & $X$ & $X$ & $\mathrm{X}$ & $X$ \\
\hline Observations & 3,642 & 3,642 & 3,642 & 3,642 & 3,642 & 3,642 \\
\hline$R^{2}$ & 0.75 & 0.77 & 0.81 & 0.81 & 0.72 & 0.80 \\
\hline
\end{tabular}

Notes: Newey-West robust standard errors reported. Dependent variable is the log of the daily number Part 1 violent and nonviolent crimes (columns 1 and 4), non-Part-1 violent and nonviolent crimes (columns 2 and 5), and all violent and nonviolent crimes (columns 3 and 6). Calendar fixed effects include year-month fixed effects, day of week fixed effects, and first-of-month, first-of-year, and holiday dummies. Weather variables include binned maximum daily temperature, binned dew point, precipitation, barometric pressure, and average sky cover. Historical mean temperature is the average maximum temperature over 1991-2000 matched by day of year to the study period. All specifications instrument for pollution using 20 degree bins for daily average wind direction at Midway Airport. The pollution variable of interest is the standardized mean reading over monitors 31-22-3 and 31-1016-3.

Consistent with the medical literature on pollution and aggressivity, the effect seems to be specific to violent crime. In columns 4 through 6 , we replicate the specifications in columns in 1 through 3 using property crimes. In column 4, in which we omit weather controls, we find a positive relationship between pollution and property crime. But, this positive estimate is biased upward by the omission of weather covariates. Once we control for weather covariates in columns 5 and 6 , the coefficients on pollution are close to zero and, although insignificant, relatively precisely estimated.

We focus on more serious, Part 1 crimes in this paper. These crimes entail greater societal costs and are more likely to be reported to police than less serious offense. Never the less, we extend the analysis above to less serious, non-Part-1 crimes reported to the CPD. Simple assault and simple battery, which typically involve minor injuries and less serious circumstances, make up the vast majority on violent crimes not classified as Part 1. Non-Part-1 nonviolent crimes include drug possession, prostitution, vandalism, and other less serious offenses. Table 3 reports the results from the IV specification for violent and nonviolent Part 1 and non-Part-1 crimes. Columns 1 and 4 recreate the IV results from Table 2, while columns 2 and 5 examine similar specifications for non-Part-1 violent and nonviolent crimes, respectively. Finally, columns 3 and 6 present results for the log of all crimes. Although magnitudes are slightly more modest, we find evidence that the number of less serious violent crimes also increases on days where wind-driven pollution impacts air quality. A 1 standard deviation increase in $\mathrm{PM}_{10}$ emissions is associated with a 1.4 percent increase in less serious violent crime and a 1.7 percent increase in violent crime in the aggregate. As for more serious property crimes, we do not find a strong relationship between the commission of less serious nonviolent crimes and wind-driven air pollution.

These city-level regressions provide suggestive evidence of a causal relationship between ambient air pollution and violent crime. Yet, they are identified entirely off 
of time series variation. If we fail to control for unobservables correlated with both wind direction and crime or misspecify the true relationship between the dependent variable and crime-related observables, we may make incorrect inferences about the causal relationship between pollution and criminal activity.

\section{Microgeographic Evidence}

To provide more compelling causal evidence, we exploit the fact that we know the specific location of each crime reported to the Chicago police. This allows us to estimate the relationship between pollution and crime by comparing local neighborhoods as they are differentially impacted by pollution. Rather than impute pollution between monitors or predict pollution from an air transport model, we use major interstate highways radiating from the center of the city as fixed sources of pollution. We examine crime in neighborhoods on either side of an interstate highway on days when the wind blows orthogonally to the direction of the interstate.

When the wind blows "across" the highway, the pollution generated from vehicles disproportionately impacts the downwind neighborhood. To demonstrate that pollution from interstates can meaningfully impact air quality, consider Figure 2 which summarizes CO readings at one of the monitors in Chicago. This monitor (31-6004-1) is located immediately north of the I-290 interstate, which runs straight west from the Chicago city center to the suburbs of Oak Park and Berwyn. Like Figure 1, the shade of the contour plot denotes mean $\mathrm{CO}$ pollution reading at the monitor as a function of vector-based net wind speed and direction. The vector and distance from the origin denote the direction from which the wind is blowing and the average wind speed, respectively. For this particular monitor, the concentration of $\mathrm{CO}$ is greatest when the wind blows from the highway toward the monitor. Since the area on the south side of the highway (immediately across from the monitor) is open space, ${ }^{21}$ we attribute the incremental pollution at the monitor when the wind is blowing from the south to the pollution from traffic on I-290. This approach allows us to employ a treatment-control framework where, on a given day, the downwind location is "treated" by pollution. The advantage of this approach is that the very local nature of the exercise allows us to use the upwind neighborhood as a control that faces identical weather conditions, plausibly addressing potential concerns with misspecification or omission of correlated weather variables. Furthermore, since the interstates in Chicago run in different directions, different neighborhoods are "treated" each day. This helps address the identification concerns with more aggregate analyses that might confound causal identification of the impact of pollution on crime. ${ }^{22}$

Our identification strategy is easiest to illustrate using I-290 as an example. To causally estimate the effect of pollution on crime, we compare crimes along the

\footnotetext{
${ }^{21}$ Forest Home Cemetery covers an area roughly three-quarters of mile east-west and a half-mile north-south on the side of I-290 immediately opposite the pollution monitor.

${ }^{22}$ Barrios et al. (2012) highlight the importance of accounting for spatial correlation beyond the level at which the treatment is assigned. Unlike the context they examine, where inference is based on individual-level outcomes and state-level treatments, the downwind treatment varies at the same level as our unit of observation (the interstate-side-day level).
} 


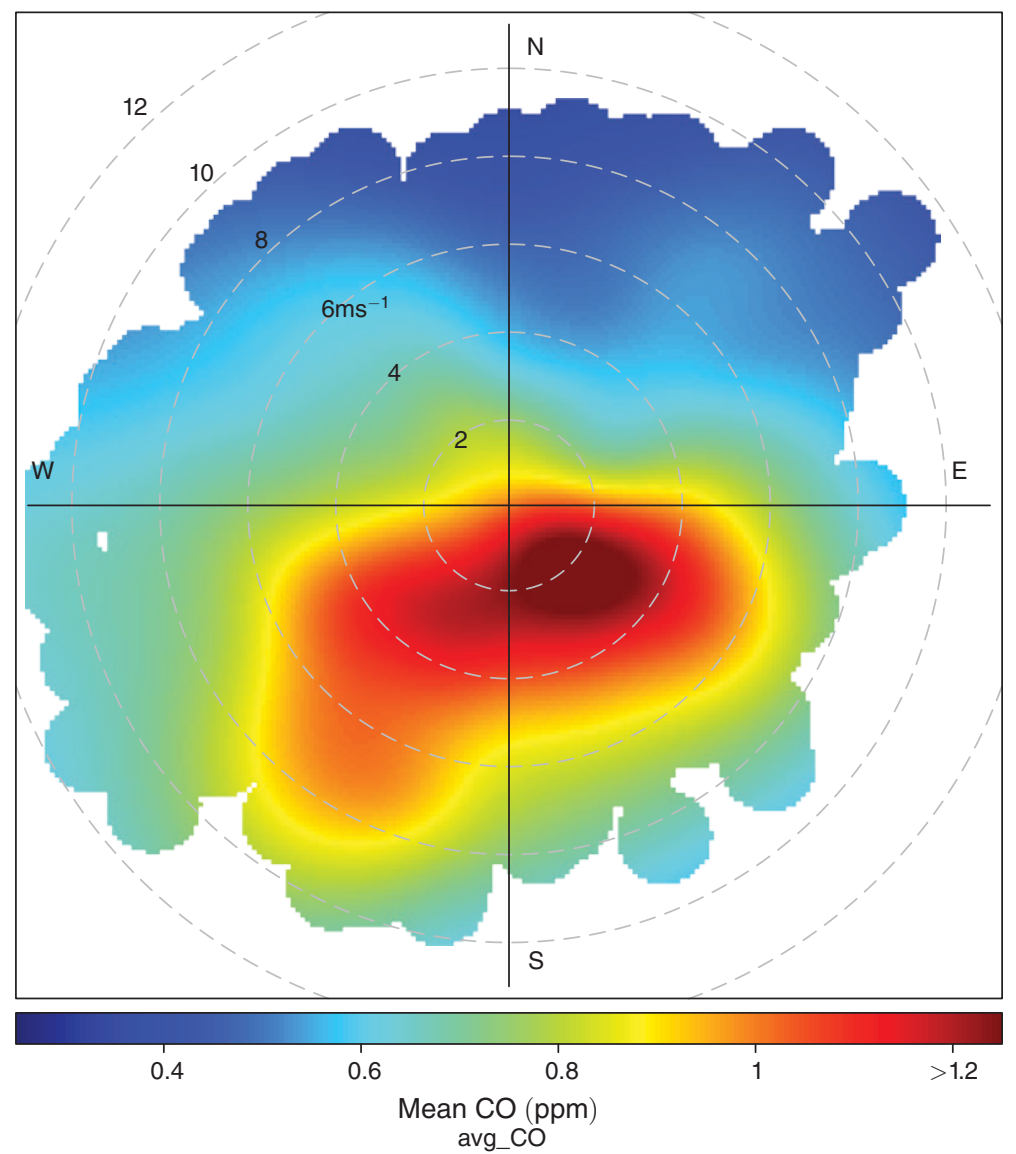

Figure 2. Average CO Reading near I-290 By Wind Direction and Vector-Based Speed

Notes: Shading denotes denote mean hourly CO readings over sample period at Monitor 31-6004-1. The vector from the origin to a particular point denotes the direction from which wind is blowing, and the distance from the origin denotes average wind speed (in meters/second). For example, the point $(0,2)$ reflects average emissions in an hour during which the wind is blowing from the east at 2 meters per second.

north side of I-290 to those along the south side of I-290 on days when the wind is blowing orthogonally to the interstate. On a day when the wind is blowing from the south, the pollution impacts the north side of I-290 and vice versa. In essence, the side of the interstate from which the wind is blowing acts as a control for unobservable daily variation in side-invariant criminal activity driven by, for example, weather. For our estimate to be biased, an omitted variable must differentially affect crime on the side of the road to which the pollution is blowing.

We extend this approach to include neighborhoods within one mile of other interstates in the Chicago area, plotted in the map in Figure 3. ${ }^{23}$ The figure plots

\footnotetext{
${ }^{23}$ We select the one-mile boundary to be inclusive of the region likely affected by downwind exposure to an interstate. Karner, Eisinger, and Niemeier (2010) present observational evidence that downwind exposure decays with distance, reaching background pollution levels within roughly one-half a kilometer for $\mathrm{NO}_{x}$ and a kilometer for $\mathrm{PM}_{2.5}$.
} 


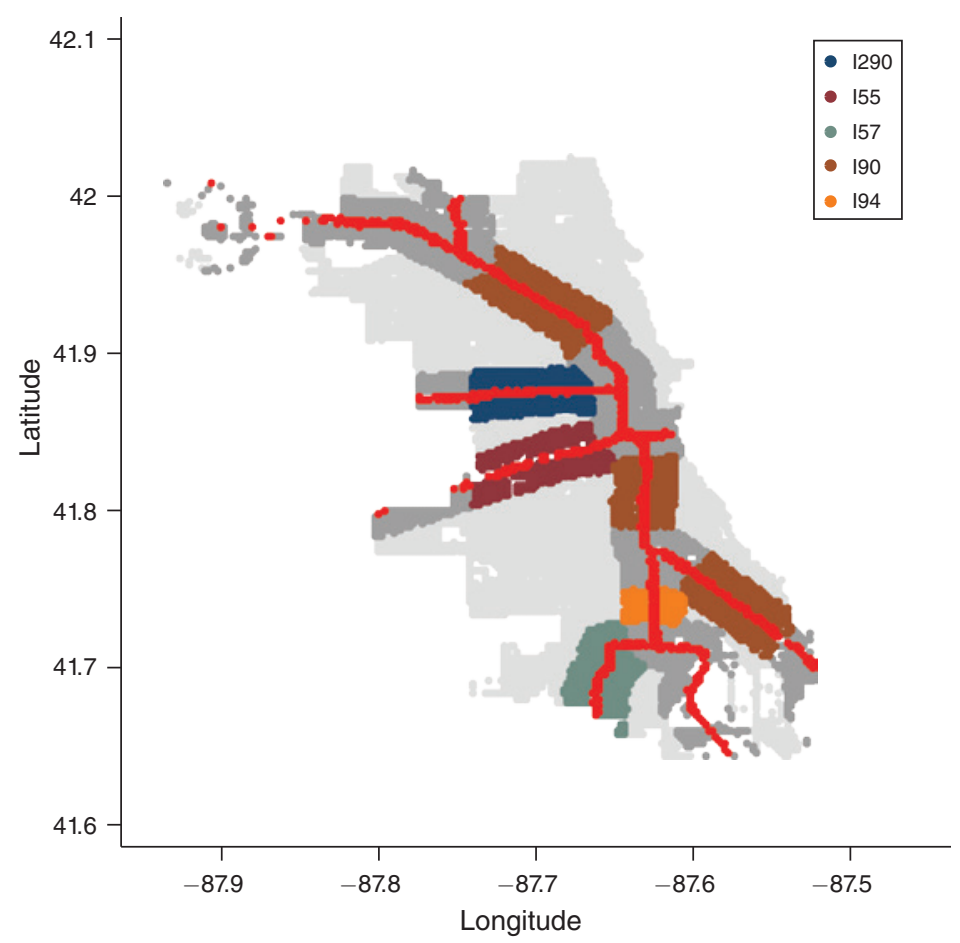

Figure 3. SAmple Set For Interstate Identification Strategy

Notes: Figure plots the latitude and longitude of all crimes in light grey, crimes within one mile of an interstate in Chicago in dark grey, the location of the interstates in red, and the seven interstate segments used for the interstate analysis in color.

the locations of all crime within one mile of the interstates, marked in red. We further limit the sample of crimes to the colored regions in Figure 3 based on several criteria. First, we drop crimes that are within one mile of more than one interstate. In these areas, a control region upwind of one interstate may be downwind from a second interstate. This excludes crime in downtown Chicago (where the major interstates converge) and crime close to the interchanges of I-90, I-94, and I-57, both north and south of the city. Second, we drop crimes in the extreme northwest and southeast of the city. The northwestern region is proximate to O'Hare International Airport. While the airport is technically part of the city of Chicago, it is connected to the rest by only a narrow strip of highway and is unlikely to be representative of criminal activity elsewhere. The southeastern part of the city borders Lake Michigan to the east and Lake Calumet to the southwest, limiting the extent of activity on the waterfront sides of I-90 and I-94. Finally, we exclude crimes on the western edges of I-55 and I-290, as we only possess information about crimes reported within the Chicago city limits. Westward of $87.74 \mathrm{~W}$ longitude, I-55 exits (and then reenters) the city, and I-290 runs along the city limits.

Finally, we focus our analysis on days during which one side of the interstate is strongly treated. In our main set of results, we consider the sample of 
interstate-segment days for which the average wind direction on a given day was within 60 degrees of the line orthogonal to the direction of the interstate. ${ }^{24}$

Our main specification regresses the number of crimes on side $s$ of interstate $i$ on day $t$ on interstate-side fixed effects, interstate-date fixed effects, and a dummy variable equal to one if side $s$ is the side downwind from interstate $i$ on day $t$. In most of our specifications, we normalize the number of crimes by the mean so as to be able to interpret the coefficient estimates as the effect of downwind exposure in terms of the percent of average crime. ${ }^{25}$ Formally,

$$
\text { Crime }_{i s t}=\alpha_{i s}+\gamma_{i t}+\beta \text { Downwind }{ }_{i s t}+\epsilon_{i s t} .
$$

Because the nature and motivation of violent and property crimes differ, we separately estimate the relationship for the two classes of crimes. Interstate-side fixed effects $(\alpha)$ control for time-invariant unobservables that are correlated with criminal activity on each side of the interstate. The interstate-date fixed effects $(\gamma)$ control for daily variation in criminal activity near each interstate. Since treatment status of a given side of an interstate varies daily, we report robust standard errors in all specifications. 26

One concern for identification is that an interstate generates other disamenities that might confound our results. One note of particular concern is that vehicles emit both noise and physical air pollutants, both of which have been linked to changes in emotional state and tendency to aggressivity in ways that might drive increases in crime. For example, Hener (2019) provides evidence of a causal effect of aircraft noise on the rate of physical assaults in the area surrounding Frankfurt airport. ${ }^{27}$ However, the use of the upwind side of the road as a control allows us to address this concern, given well-established research documenting that the dispersion of traffic noise is largely insensitive to wind patterns in urban environments. Shu, Yang, and Zhu (2014) measure noise pollution in the vicinity of two major freeways in Los Angeles and find that "residents who live on the dominantly downwind side are exposed to . . . similar noise level when compared to the residents who live on the upwind side" (137). Weber (2009) finds that the spatial distribution of noise measured across different days in the vicinity of major roads in Essen, Germany, was invariant to wind direction. Allen et al. (2009) repeatedly measured noise at 69 sites within 500 meters of major roads in Chicago and 46 in Riverside County, California, under varying wind conditions. The rate of decay of noise with respect to distance upwind from roads was not significantly different from that on

\footnotetext{
${ }^{24}$ Online Appendix figure A.7 illustrates how we classify upwind and downwind interstate segments.

${ }^{25} \mathrm{We}$ also present estimates using the number of crimes and a Poisson count model in online Appendix Table A.1. The results are qualitatively identical.

${ }^{26}$ In online Appendix table A.2, we also calculate Newey-West standard errors, errors clustered by interstate-side month, and errors clustered by interstate-side year. We find little evidence that robust standard errors overstate our statistical precision as a result of serial correlation.

${ }^{27}$ While Hener (2019) exploits plausibly exogenous variations in wind direction as part of his identification strategy, this is not because noise is itself wind carried. Rather, safety rules regarding aircraft movements in the European Union cause switches between westbound- and eastbound-approach landings at Frankfurt airport in response to changes in wind conditions. This varies the set of surrounding communities under the flight path and therefore "treated" to noise at any given time.
} 
TABle 4 -CRime Downwind of Interstates

\begin{tabular}{|c|c|c|c|c|}
\hline & (1) & (2) & (3) & (4) \\
\hline $\begin{array}{l}\text { Panel A. Violent crime } \\
\text { Treatment (downwind) }\end{array}$ & $\begin{array}{c}0.0558 \\
(0.0108)\end{array}$ & $\begin{array}{c}0.0186 \\
(0.0094)\end{array}$ & $\begin{array}{c}0.0186 \\
(0.0089)\end{array}$ & $\begin{array}{c}0.0188 \\
(0.0091)\end{array}$ \\
\hline $\begin{array}{l}\text { Route } \times \text { side fixed effects } \\
\text { Route } \times \text { date fixed effects } \\
\text { Route } \times \text { side weather interaction }\end{array}$ & & $X$ & $\begin{array}{l}X \\
X\end{array}$ & $\begin{array}{l}X \\
X \\
X\end{array}$ \\
\hline $\begin{array}{l}\text { Observations } \\
R^{2}\end{array}$ & $\begin{array}{c}41,730 \\
0.001\end{array}$ & $\begin{array}{c}41,730 \\
0.274\end{array}$ & $\begin{array}{c}41,730 \\
0.678\end{array}$ & $\begin{array}{c}41,720 \\
0.680\end{array}$ \\
\hline $\begin{array}{l}\text { Panel B. Property crime } \\
\text { Treatment (downwind) }\end{array}$ & $\begin{array}{c}0.0015 \\
(0.0071)\end{array}$ & $\begin{array}{r}-0.0014 \\
(0.0046)\end{array}$ & $\begin{array}{r}-0.0014 \\
(0.0041)\end{array}$ & $\begin{array}{r}-0.0007 \\
(0.0043)\end{array}$ \\
\hline $\begin{array}{l}\text { Route } \times \text { side fixed effects } \\
\text { Route } \times \text { date fixed effects } \\
\text { Route } \times \text { side weather interaction }\end{array}$ & & $X$ & $\begin{array}{l}X \\
X\end{array}$ & $\begin{array}{l}X \\
X \\
X\end{array}$ \\
\hline $\begin{array}{l}\text { Observations } \\
R^{2}\end{array}$ & $\begin{array}{c}41,730 \\
0.000\end{array}$ & $\begin{array}{c}41,730 \\
0.609\end{array}$ & $\begin{array}{c}41,730 \\
0.841\end{array}$ & $\begin{array}{c}41,720 \\
0.843\end{array}$ \\
\hline
\end{tabular}

the downwind side, leading the authors to conclude that while concentrations of the physical air pollutants - which they also monitored-were wind sensitive, "in contrast, noise had similar distance decay relationships upwind, and the similarity of 5-minute noise measurements made ... in different seasons (and with different wind characteristics) provides further evidence that noise is minimally impacted by wind direction" (Allen et al. 2009, 341). ${ }^{28}$

\section{A. Results}

We present main results for violent crime (panel A) and property crime (panel B) in Table 4. Columns 1 and 2 report the effect without the inclusion of route-side and route-day fixed effects. Column 3 corresponds to the specification in equation (3).

Focusing first of violent crime in panel A, moving column 1 to column 2, we find that the omission of route-side fixed effects positively biases the estimate of the downwind treatment effect, consistent with the predominately downwind side of the interstate experiencing a higher rate of violent crime irrespective of wind direction. Controlling for both route-side and route-day fixed effects, we find that violent crime increases by about 1.9 percent on the downwind side of the interstate.

A remaining threat to identification arises if we omit a variable correlated with wind direction that differentially affects crime on one side of the interstate. Using I-290 as an example, suppose that the wind only blows from the south on hot summer

\footnotetext{
${ }^{28}$ This is echoed by the Traffic Noise Model required by the Federal Highway Administration for traffic noise studies that don't explicitly model prevailing wind direction for simulating the road noise impacts and by other papers examining the downwind impacts of roadways (e.g., Anderson 2020).
} 
days and houses on the north side of I-290 are much less likely to have air conditioning than houses on the south side of I-290. We might observe a relative increase in crime on the north side of the I-290 when the wind is blowing from the south due to not pollution but rather increased exposure to high temperatures.

This seems an unlikely threat to identification. The seven interstate segments we examine transect different parts of the city of Chicago with different socioeconomic characteristics. Furthermore, the interstate segments travel in different directions. To bias our estimates, such a story would have to hold for different regions of the city with different demographics, some of which are east and west of an interstate and some of which are north and south of an interstate. Nevertheless, we can address the concern directly by allowing the number of crimes on each of the 14 interstate sides to vary independently with temperature and precipitation. Conceptually, this identifies the downwind effect by comparing the number of crimes on opposite sides of an interstate on days that have identical weather conditions but face different levels of pollution as a result of wind direction. Formally, we estimate

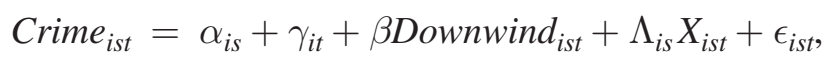

where $X_{\text {ist }}$ includes the maximum temperature over the course of the day and precipitation over the course of the day, and present the estimates in column 4.

We find little evidence that these additional controls explain our results in column 3 . When we allow for criminal activity on the each side of the road to vary independently with temperature and precipitation, our estimates are almost identical: violent crime increases by roughly 1.9 percent on the downwind side relative to mean levels of violent crime.

Panel B of Table 4 presents the results of identical specification for property crime rather than violent crime. As in the city-level regressions, we find no evidence that pollution impacts property crime. Although our estimates are indistinguishable from zero, they are relatively precisely estimated, suggesting little relationship between pollution and property crime.

Effects by Subcategory of Violent Crime.-Although we aggregate violent crimes in our main specification, violent crimes differ substantially with respect to their nature and cost. In addition, violent crimes escalate in severity, specifically aggravated assault and aggravated battery. An assault is characterized by the threat of bodily harm, defined as "an unlawful attack by one person upon another wherein the offender displays a weapon in a threatening manner, placing someone in reasonable apprehension of receiving a battery," whereas battery is the infliction of bodily harm, defined "an unlawful attack by one person upon another wherein the offender uses a weapon or the victim suffers obvious severe or aggravated bodily injury involving apparent broken bones, loss of teeth, possible internal injury, severe laceration, or loss of consciousness." 29

\footnotetext{
${ }^{29}$ Definitions of FBI index crimes are given at https://ucr.fbi.gov/crime-in-the-u.s/2010/crime-in-the-u.s.-2010/ offense-definitions.
} 
Table 5-Violent Crime Downwind of Interstates, by Specific Crime

\begin{tabular}{lcccc}
\hline \hline & Homicide & Rape & $\begin{array}{c}\text { Aggravated } \\
\text { assault } \\
(1)\end{array}$ & $\begin{array}{c}\text { Aggravated } \\
\text { battery } \\
(4)\end{array}$ \\
\hline Treatment (downwind) & $(2)$ & 0.00310 & -0.0119 & 0.0299 \\
& $(0.00185)$ & $(0.00293)$ & $(0.00610)$ & $(0.00862)$ \\
Dependent variable mean & 0.029 & 0.083 & 0.338 & 0.638 \\
Route $\times$ side fixed effects & $\mathrm{X}$ & $\mathrm{X}$ & $\mathrm{X}$ & $\mathrm{X}$ \\
Route $\times$ date fixed effects & $\mathrm{X}$ & $\mathrm{X}$ & $\mathrm{X}$ & $\mathrm{X}$ \\
Route $\times$ side weather interaction & $\mathrm{X}$ & $\mathrm{X}$ & $\mathrm{X}$ & $\mathrm{X}$ \\
Observations & & & 41,720 & 41,720 \\
$R^{2}$ & 41,720 & 41,720 & 0.563 & 0.651 \\
\hline
\end{tabular}

Notes: Robust standard errors reported. The dependent variable is the number of crimes within one mile of one side of the interstate. A side of the interstate is considered downwind if the average wind vector over the course of the day is within 60 degrees of the vector orthogonal to the direction of the interstate. All specifications include interstate $\times$ date fixed effects and interstate $\times$ side fixed effects interacted with daily maximum temperature and total precipitation.

In Table 5, we estimate effects for the individual violent crimes. To directly compare the coefficients, our specification uses the number of crimes (rather than crimes as a percentage of mean crime levels) as the dependent variable. ${ }^{30}$ We find evidence that the aggregate increase in violent crime from downwind exposure masks an increase in reports of aggregated battery offset by a decrease in aggregated assaults. One interpretation of these results is that pollution causes a net increase in violent crime but also results in marginal assaults escalating into batteries. While the coefficients on murder and forcible rape are positive, the effects on both are less precisely estimated.

\section{B. Supporting Evidence of Wind-Driven Pollution}

One advantage of the microgeographic analysis is that we can examine whether the estimate of the treatment effect varies in a way that is consistent with downwind pollution exposure as the mechanism. To begin, we examine how the estimated treatment effect varies with the two sample restrictions that underpin the results in Table 4. When constructing the sample for the main results, we limited the sample to days during which the average wind vector over the course of the day was within 60 degrees of the vector orthogonal to the direction of the road. If the criterion for inclusion is less strict (i.e., the angle is greater than 60 degrees), a side of an interstate might be classified as "treated" on days with less intensive downwind exposure. Such inclusion would tend to attenuate the treatment effect. ${ }^{31}$

\footnotetext{
${ }^{30}$ We present a similar table for property crimes in the online Appendix as Table A.7. As with our aggregate results, we find little evidence that subcategories of property crime increase on the downwind side of an interstate.

${ }^{31}$ As an illustration, consider the most inclusive possible rule, where the angle of inclusion was 90 degrees. In this case, if the average wind vector over the course of a day blows at all toward one side of the interstate, we consider that side treated on that particular day. Using I-290 once again as an example, if the wind fluctuated from due northwest to due southwest but the average wind vector was 271 degrees, the most generous inclusion rule would classify the north side of the road as treated despite pollution affecting both sides of the road.
} 
Table 6-Violent Crime Downwind of Interstates, by Treatment Angle and Distance FROM INTERSTATE

\begin{tabular}{lccccc}
\hline \hline Angle width & 36 & 45 & 60 & 75 & 90 \\
\hline Quarter-mile & & & & & \\
$\quad$ Estimate & 0.0076 & 0.0113 & 0.0138 & 0.0101 & 0.0091 \\
$\quad$ Standard error & $(0.0069)$ & $(0.0060)$ & $(0.0051)$ & $(0.0044)$ & $(0.0040)$ \\
$\quad$ Observations & 24,754 & 31,242 & 41,720 & 51,910 & 61,348 \\
$R^{2}$ & 0.579 & 0.582 & 0.588 & 0.587 & 0.588 \\
& & & & & \\
Half-mile & & & & & \\
$\quad$ Estimate & 0.0145 & 0.0168 & 0.0161 & 0.0156 & 0.0165 \\
$\quad$ Standard error & $(0.0105)$ & $(0.0092)$ & $(0.0077)$ & $(0.0067)$ & $(0.0061)$ \\
Observations & 24,754 & 31,242 & 41,720 & 51,910 & 61,348 \\
$R^{2}$ & 0.637 & 0.638 & 0.642 & 0.641 & 0.64 \\
& & & & & \\
One mile & & & & & 0.0154 \\
$\quad$ Estimate & 0.0248 & 0.0236 & $\mathbf{0 . 0 2 3 4}$ & 0.0168 & $0.0090)$ \\
Standard error & $(0.0153)$ & $(0.0134)$ & $\mathbf{( 0 . 0 1 1 3})$ & $(0.0099)$ & $0.0090)$ \\
Observations & 24,754 & 31,242 & $\mathbf{4 1 , 7 2 0}$ & 51,910 & 61,348 \\
$R^{2}$ & 0.676 & 0.678 & $\mathbf{0 . 6 8}$ & 0.68 & 0.679 \\
\hline
\end{tabular}

Notes: Robust standard errors reported. The dependent variable is the number of crimes within one mile of one side of an interstate. All specifications include interstate $\times$ date fixed effects and interstate $\times$ side fixed effects interacted with daily maximum temperature and total precipitation. The estimate using assumptions equivalent to those in Table 4, panel A, column 4, is emboldened. For reference, the mean number of violent crimes at the interstate-side-day level is 0.225 within a quarter-mile, 0.486 within a half-mile, and 1.061 within a full mile.

The second sample restriction is the distance on either side of an interstate we consider when counting the number of crimes. In our main results, we include crimes within one mile of either side of the interstate. But, observational evidence in Karner, Eisinger, and Niemeier (2010) suggests that downwind pollution exposure decays with distance, reaching background levels for most pollutants within a kilometer. ${ }^{32}$ In our context, if pollution is the driving mechanism, we should expect the marginal effect to decreases with distance to the highway.

Table 6 presents the results of estimating the specification from column 4 of Table 4 as we vary the inclusion restrictions. Here, we use the number of crimes as our dependent variable so as to directly compare the downwind impacts in levels across different inclusion restrictions. Each cell reports the estimated treatment effect from a separate regression. The columns correspond to the different angles necessary to qualify as "downwind," while the rows correspond to the size of the "collar" drawn around each interstate highway. For example, the top-leftmost cell reports the treatment effect estimated using crimes that happen within 1 quarter-mile of an interstate only using days during which the average wind vector is within 36 degrees of the vector orthogonal to the direction of the highway (the most restrictive inclusion rule considered). Moving to the left in the table, we gradually relax the angle necessary for inclusion in the sample. Moving down, we extend the collar around the interstate to consider crimes within a one-half-mile distance and a one-mile distance, respectively. The estimate of the effect on the number of downwind crimes using sample

\footnotetext{
${ }^{32}$ Examining outcomes, Anderson (2020) focuses on a narrow band around the interstate.
} 
inclusion restrictions from the main specification (that in column 4 from Table 4) is highlighted in bold. ${ }^{33}$

Although not dispositive, the results are broadly consistent with what we would expect if pollution were the driving mechanism. Extending the angle for inclusion increases the size of the estimation sample. While this improves the precision of the estimates (moving from left to right across the table, standard errors monotonically decline), increasing the angle for inclusion tends to attenuate the point estimate of the downwind effect, especially as we move toward the most generous values. This result is analogous to the attenuation of an intent-to-treat estimate caused by noncompliance. Moving down the rows of estimates, the size of the band on either side of the interstate varies between one quarter-mile and one mile. Although the area of the area of the study region doubles as we increase the bounds from one quarter-mile to one half-mile and then from one half-mile to one mile, the estimated treatment effect does not increase commensurately. This suggests that the downwind impacts are greatest near the roadway and that the marginal effect on crime diminishes with distance to the interstate, consistent with the observational evidence in Karner, Eisinger, and Niemeier (2010)..$^{34}$

As a second test of pollution as the driving mechanism, we also examine the timing of treatment. Much of the literature examining the short-run impacts of pollution on health (e.g., Schlenker and Walker 2016) and productivity (e.g., Zivin and Neidell 2012, Chang et al. 2019) documents the immediate (and short-lived) impacts of pollution exposure, noting that deleterious impacts arise from contemporaneous rather than lagged exposure. As a test, we regress crime on a particular day on comtemporaneous treatment as well as seven leads and lags of the treatment. We plot the coefficient estimates for past, contemporaneous, and future treatment in Figure $4{ }^{35}$ The coefficient estimates for lagged treatment are all indistinguishable from zero, consistent with the previous literature that suggests short-lived impacts of pollution exposure. In addition, the coefficients on future treatment status are also indistinguishable from zero, as would be expected by their placebo status.

Finally, if downwind exposure is the mechanism driving our observed effects, we might also expect the effect of downwind exposure to increase in seasons and days of the year where people are more likely to be outside and exposed to the pollution. In Figure 5, we graph the coefficients and 95 percent confidence intervals for treatment effects that vary by season (top) and daily maximum temperature bin

\footnotetext{
${ }^{33}$ The point estimate is different from that in the main specification, since here we use the number of crimes as the dependent variable. Normalizing by the mean number of crimes, we obtain the point estimate from Table 4 , panel A, column 4.

${ }^{34}$ As a further check, in online Appendix Section II, we demonstrate that the downwind effect of pollution is strongest and most cleanly estimated on days during which the wind is blowing between 5 and 10 miles per hour $(\mathrm{mph})$. This is consistent with observational evidence from the wind rose in Figure 2 that suggests that downwind pollution readings peak with wind speeds of roughly 2-4 meters per second (5-10 mph). At these speeds, the wind is sufficiently strong to ensure that the pollution is pushed to one side of the road. But, at higher speeds, pollution is dispersed more quickly.

${ }^{35}$ We also present a lagged version of our main specification in the online Appendix that includes leading and lagging values of the treatment variable (as well as lagged values of crime). As in Figure 4, leading and lagging values of the downwind treatment are uncorrelated with violent crime, although consistent with Jacob, Lefgren, and Moretti (2007), we find evidence that crime is serially correlated. Moreover, the coefficient on the contemporaneous value of the downwind treatment is virtually unchanged with the inclusion of lagged treatment variables, again consistent with the hypothesis that it is contemporaneous exposure as the driving mechanism.
} 


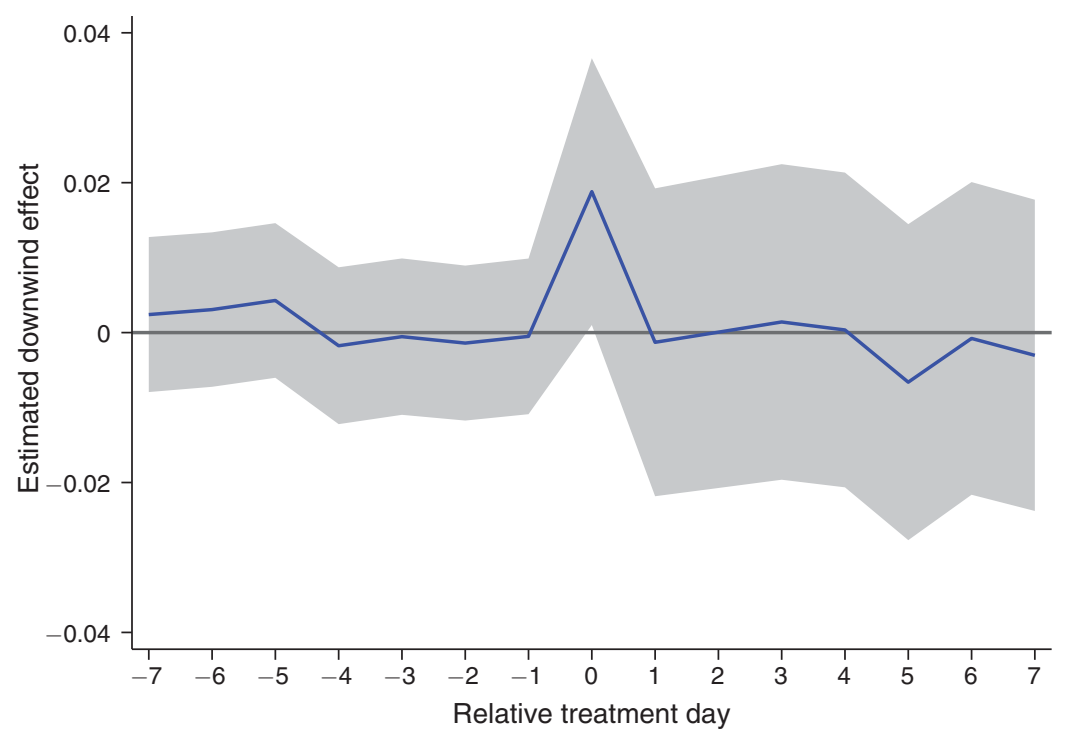

Figure 4. Leading and Lagging Downwind Treatment EfFects

Notes: Figure plots the coefficient estimates and 95 percent confidence interval of lagged and leading downwind treatment dummies. The dependent variable is the number of crimes within one mile of one side of the interstate normalized by the mean number of crimes. All specifications include interstate $\times$ date fixed effects and interstate $\times$ side fixed effects interacted with daily maximum temperature and total precipitation.

(bottom). ${ }^{36}$ On each plot, the dotted horizontal line corresponds to the treatment effect from our main specification, Table 4, panel A, column 4.

Although estimating separate coefficients for each season and temperature bin reduces the statistical power of our results substantially, we find results generally consistent with downwind outdoor exposure as the mechanism. Across the four specifications, the effect of being downwind of the interstate has the largest impact during the spring and summer months. Relative to the 1.9 percent increase in violent crimes over the entire year, being the downwind side of the interstate is associated with a 3 to 5 percent increase in violent crime in the spring and summer. In contrast, the winter and fall treatment effects are not statistically significant after conditioning on fixed effects. In a similar vein, the relationship between temperature and the downwind treatment effect is generally concave and peaks on comfortable days with maximum daily temperatures between $20-24^{\circ}$ Celsius $\left(68-75^{\circ}\right.$ Fahrenheit).

\section{Placebo Interstate Test}

The local nature of our identification strategy also allows for a placebo test of road pollution as the mechanism. To motivate the placebo test, consider the following

\footnotetext{
36 The specifications in green include interstate $\times$ date fixed effects and correspond to the specification in column 3 of 4 . The specifications in red additionally include interstate $\times$ side fixed effects interacted with daily maximum temperature and total precipitation and correspond to the specification in column 4 of Table 4 . For completeness, we report the full regression tables in online Appendix tables A.4 and A.5, respectively.
} 

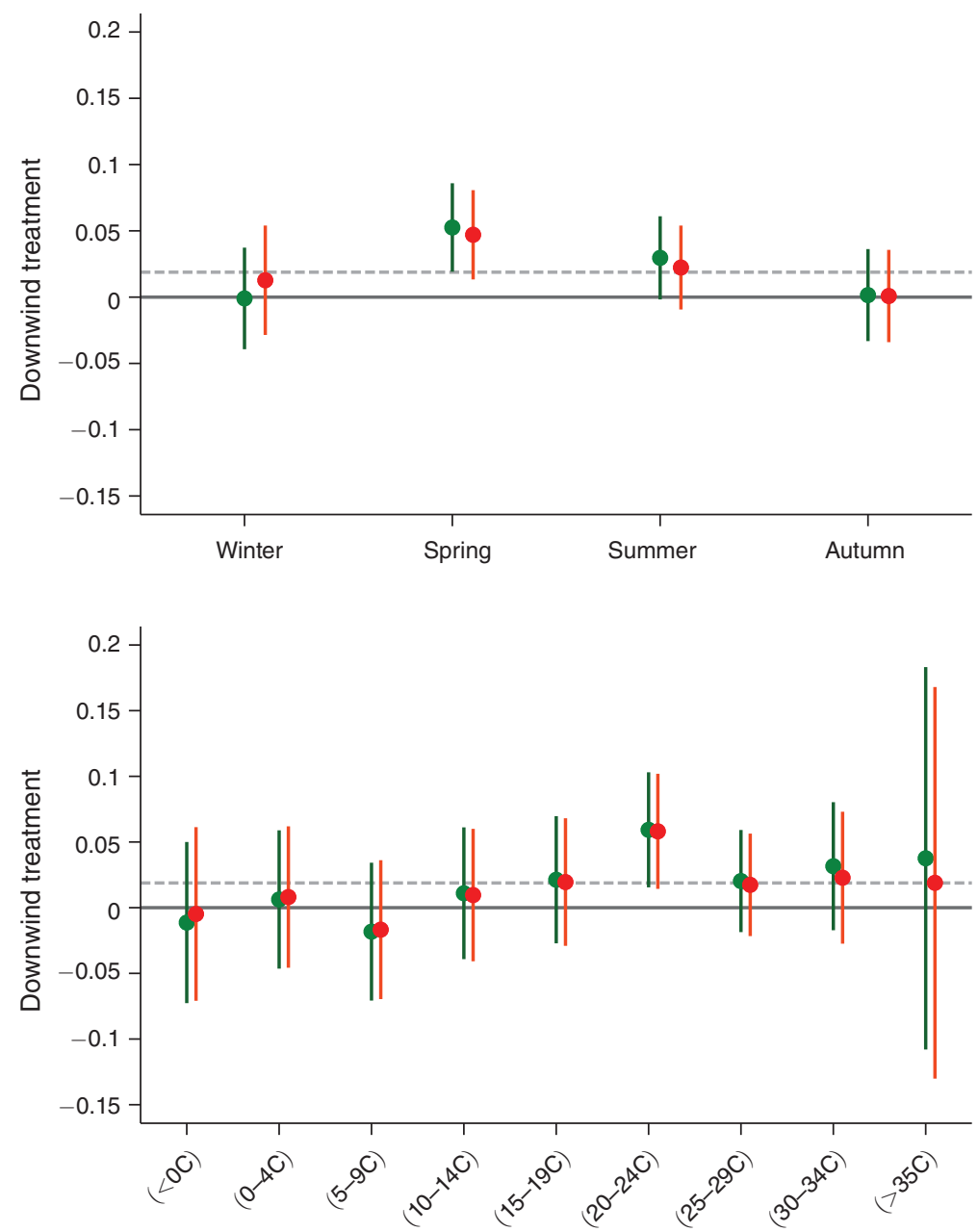

Figure 5. Downwind Coefficients, by Season and Temperature

Notes: Figure plots the coefficient estimates and 95 percent confidence intervals for interactions between the downwind treatment and season of the year (top) and daily temperature bins (bottom). The dependent variable is the number of crimes within one mile of one side of the interstate normalized by the mean number of crimes. The specifications in green include interstate $\times$ date fixed effects and correspond to the specification in column 3 of 4 . The specifications in red additionally include interstate $\times$ side fixed effects interacted with daily maximum temperature and total precipitation and correspond to the specification in column 4 of Table 4 . The dotted horizontal line denotes the point estimate of the downwind treatment (0.188) from Table 4. For completeness, the underlying regression results are reported in the online Appendix.

thought exercise. Suppose we did not know ex ante the latitude at which I-290 cuts straight east-west through the city of Chicago. We could estimate downwind coefficients from our model at a number of different latitudes. We could then examine whether the effect on violent crime of being downwind was greatest at the latitude of I-290. If we found large effects at alternative latitudes, we might worry that our downwind treatment was capturing effects other than pollution from mobile sources.

To conduct the exercise, we focus on crimes at similar longitudes to the crimes in our sample set for I-290, but extending far north and south of I-290. Figure 6 maps 


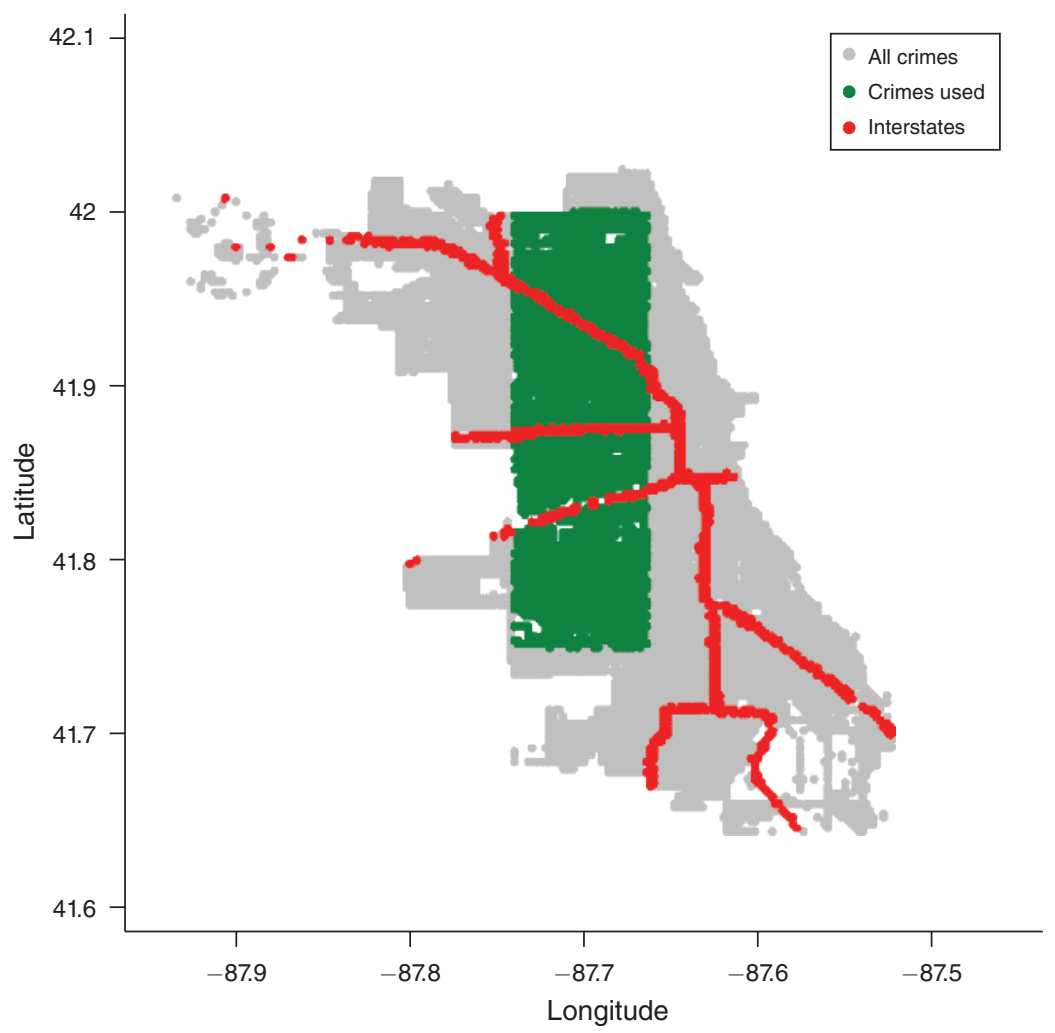

Figure 6. Sample Set for Falsification Test

Note: Figure plots the latitude and longitude of all crimes in Chicago in grey, the sample set of crimes used for the analysis of the placebo interstates in green, and the location of the interstates in red.

the latitude and longitudes of the crimes we use for the falsification test in green and the location of the interstates in red. Moving from the south to the north in one-mile increments, we consider alternative latitudes. At each latitude, we conduct a $t$-test equivalent to the main specification in equation (3). We calculate the daily difference in violent crimes one mile north of the alternative latitude to that one mile south of the latitude. We then test whether the north-south violent crime differential at each latitude is greater on days when the wind blows to the north than on days when the wind blows to the south.

Figure 7 plots the difference in the north-south violent crime differential on days when the wind is blowing north at each alternative latitude. The interpretation of the point estimate is identical to the interpretation of the downwind treatment in column 3 of Table 4, although in this case, the exercise only examines one of the seven interstate segments. ${ }^{37}$ Three points in particular stand out. First, the maximum estimated downwind effect (in the center of the graph) is exactly at the latitude that

\footnotetext{
${ }^{37}$ We focus on I-290 for the falsification test, as the city of Chicago extends further to the north and south than to the east and west. Thus, we can create the greatest number of "placebo interstates" to I-290.
} 


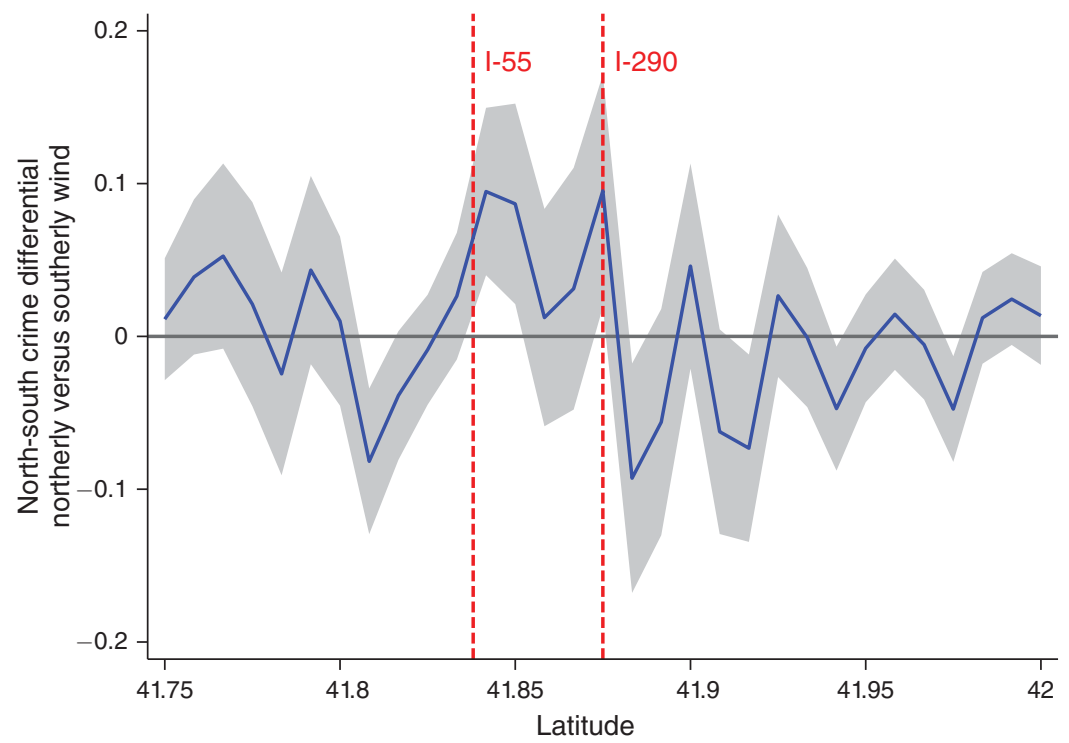

Figure 7. North-South Crime Differential, Alternative Latitudes

Notes: The $y$-axis reports the difference in the number of violent crimes one mile north versus one mile south of the latitude reported on days when the wind is blowing northernly rather than southernly. Northernly and southernly are defined as within 60 degrees of north and south, respectively. The solid line denotes the point estimate of the difference and the dashed lines denote the upper and lower bounds of the 95 percent confidence interval of the $t$-test. The vertical lines denote the latitudes of I-290 and the average latitude of I-55.

I-290 cuts east-west through Chicago. Second, just to the right of the peak, corresponding to a latitude one mile north of I-290, we find the lowest estimated value for the downwind effect. This is exactly what we would expect if winds from the south blow pollution from I-290 onto the south side of the placebo latitude one mile north of I-290. ${ }^{38}$ The sharp rebound at latitudes just north of the minimum estimated downwind effect is also reassuring. This is consistent with the source of pollution being local to the latitude at which I-290 cuts through Chicago from east to west and dispersing at latitudes further north. Finally, the second-highest peak on the graph (at a latitude $41.84 \mathrm{~N}$ ) is roughly at the the latitude of I-55 as it passes through the falsification test region.

\section{Alternative Identification Strategy}

As a final analysis, we consider an alternative identification strategy that exploits a different source of wind-induced variation. In the main specification, we included route-side and route-date fixed effects. Thus, our main estimates compare crime on

\footnotetext{
${ }^{38}$ This, incidently, provides evidence counter to the hypothesis that the impacts are driven by downwind noise propagation. The Chicago Transit Authority Green line is an elevated light rail line that runs parallel to I-290 roughly one mile north of I-290 and generates significant noise pollution (see e.g., https://rosap.ntl.bts.gov/view/ dot/10143/dot_10143_DS1.pdf). If our downwind impacts reflect noise pollution, one might expect elevated levels of violent crime downwind of this placebo latitude rather than the diminished levels actually observed.
} 
the "treated" downwind side of the interstate to the upwind "control" region on the same day.

As an alternative, we exploit the length of our panel and compare crime within the same region on the same day of the year (e.g., the north side of I-290 on July 4) across different years. That is, if a given side of an interstate is downwind for a higher fraction of hours on a particular day (say, July 4, 2011) than on the typical July 4, we test whether we observe an increase in violent crime.

Relative to the identification strategy that uses the upwind side of an interstate as a control for crime on the downwind side, this approach directly addresses seasonal unobservables correlated with both criminal activity and prevailing wind patterns. For example, suppose that for whatever reason, people flock to the north side of I-290 on July 4 and, moreover, that side of the interstate tends to be downwind at that time of the year. Using the identification strategy that leverages opposite sides of the interstate, we might misattribute to pollution the uptick in crime arising from the July 4 uptick in activity. While, admittedly, this might be unlikely given the seven interstate segments we examine, the alternative identification strategy addresses this concern directly by identifying the effect from variation in downwind exposure of the same location on the same day of the year.

Formally, for interstate $i$, side $s$, day-of-year $d$, and date $t$, we estimate

$$
\text { Crime }_{i s t}=\alpha_{i s d}+\beta \text { Downwind }_{i s t}+\Lambda X_{i t}+\epsilon_{i s t},
$$

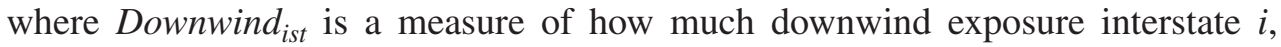
side $s$ receives on a given date $t$ and $X_{i t}$ includes weather covariates. We also include interstate-side-day-of-year fixed effects to capture the average level of violent crime on a side of an interstate on a particular day of the year (i.e., the north side of I-290 on July 4).

We construct two measures of daily downwind pollution exposure. First, we use the fraction of hours of a given day that the wind was blowing to that side of the road. In any given hour, we classify a side of the road as either treated or not treated if the wind is blowing toward the side at all, akin to the most generous inclusion rule for our main specification. We average the hourly values over the course of the day. This measure varies from zero to one, reflecting steady winds either away from or toward a particular side, respectively. As an alternative, we allow magnitude of the hourly treatment to vary based on the wind vector relative to the direction of the interstate. As suggested by Figure 2, pollution readings just north of I-290 are greatest when the wind blows from the south. Pollution readings are slightly more modest when the wind blows parallel to the road. Intuitively, if the wind blows directly toward one side, this treats a side more strongly than if the wind is blowing at an angle, relative to the vector of orthogonality. Thus, in each hour, we calculate the cosine of the angle of the wind relative to the angle of orthogonality. This creates a continuous hourly variable equal to 1 if the wind is blowing directly toward one side of the interstate and -1 if the wind is blowing directly the side of the interstate, which we average to create a daily measure.

Table 7 presents the results. In the first three columns, we present the results using the fraction of hours of the day the wind was blowing to that side of the road as our 
Table 7-Violent Crime Downwind of Interstates, Alternative Specification

\begin{tabular}{|c|c|c|c|c|c|c|}
\hline & \multicolumn{3}{|c|}{ Fraction of hours } & \multicolumn{3}{|c|}{ Average cosine of wind vector } \\
\hline & (1) & (2) & (3) & (4) & (5) & (6) \\
\hline Treatment (downwind) & $\begin{array}{c}0.0225 \\
(0.00942)\end{array}$ & $\begin{array}{c}0.0238 \\
(0.0103)\end{array}$ & $\begin{array}{c}0.0239 \\
(0.0101)\end{array}$ & $\begin{array}{c}0.0182 \\
(0.00676)\end{array}$ & $\begin{array}{c}0.0180 \\
(0.00739)\end{array}$ & $\begin{array}{c}0.0180 \\
(0.00717)\end{array}$ \\
\hline $\begin{array}{l}\text { Route } \times \text { side } \times \text { month fixed effects } \\
\text { Route } \times \text { side } \times \text { DoY fixed effects } \\
\text { Covariate interactions }\end{array}$ & $\mathrm{X}$ & X & $\begin{array}{l}X \\
X\end{array}$ & X & $X$ & $\begin{array}{l}X \\
X\end{array}$ \\
\hline $\begin{array}{l}\text { Observations } \\
R^{2}\end{array}$ & $\begin{array}{c}61,362 \\
0.301\end{array}$ & $\begin{array}{c}61,362 \\
0.356\end{array}$ & $\begin{array}{c}61,348 \\
0.369\end{array}$ & $\begin{array}{c}61,362 \\
0.301\end{array}$ & $\begin{array}{c}61,362 \\
0.356\end{array}$ & $\begin{array}{c}61,348 \\
0.369\end{array}$ \\
\hline
\end{tabular}

Notes: Robust standard errors reported. The dependent variable is the number of crimes within one mile of one side of the interstate normalized by the mean number of crimes. Columns 1 through 3 calculate daily downwind exposure as the fraction of hours a neighborhood is downwind of an interstate on a particular day. Columns 4 through 6 calculation daily downwind exposure as the mean cosine of the angular difference of the hourly wind vector relative and the vector orthogonal to the direction of the interstate segment (which varies from 1 to -1 for completely upwind and downwind days).

treatment variable. Using the fraction of downwind hours (in columns 1 through 3 ) as a measure of treatment intensity, we find that a route side has 2.4 percent more violent crimes on a day when it is downwind for every hour than on a day when it is upwind for every hour. Refining the measure of downwind exposure in columns 4 through 6 doesn't fundamentally change our conclusions. As the treatment variable varies from -1 (i.e., completely downwind) to 1 (i.e., completely upwind), we estimate a 3.6 percent increase in violent crime. These magnitudes are very similar to those in our main specification, even though the exogenous variation in wind exposure is coming from a comparison with a different implicit control group, namely the same side of the interstate on the same day of the year, but in years in which the segment was more or less "downwind."

\section{Policy Implications}

Our finding of a causal relationship between pollution and violent crime has two clear policy consequences. First, a Pigouvian tax or external cost estimate for local pollutants excluding the cost of crime would be understated. Second, our results contribute to the growing literature that suggests that pollution exposure might have adverse effect on cognition and behavior that extend more widely than previously considered.

Although we estimate that the effect of pollution on crime is modest in percentage terms, the annual aggregate costs of crime are enormous. Estimates from the literature vary in magnitude: more conservative estimates suggest crime imposes external costs of several hundred billion dollars per year annually in the United States, while the upper end of estimates (Anderson 1999) puts the aggregate cost of crime at over one trillion dollars annually.

Our paper provides two estimates of the crime costs generated by exposure to pollution. Focusing specifically on our estimates of downwind pollution exposure from interstates, we can compute a back-of-the-envelope estimate of the additional annual cost of crime from downwind exposure to major interstates. Although focused very specifically on a subset of urban neighborhoods close to interstates, this estimate 
speaks to a growing literature that studies variation in pollution exposure at the submetropolitan level. To do so, we apply cost of crime estimates from the literature and work under the conservative assumption that all additional violent crimes are assaults. ${ }^{39}$ We also conduct the back-of-the-envelope calculation under the assumption that pollution exposure doesn't shift the timing of criminal activity or the location of crimes. We find little evidence of intertemporal shifting (as the estimates of lagged effects of downwind exposure are all close to and indistinguishable from zero), but the local nature of our identification strategy makes similar tests of spatial shifting difficult. To the extent that crime shifts from the upwind to the downwind side of an interstate in response to wind direction, we would overestimate the true cost. ${ }^{40}$ Scaling our estimates from Chicago up to the United States, we estimate annual costs of crime associated with downwind interstate pollution at $\$ 178$ million per year. As a point of reference, these estimates are of roughly similar magnitude to the cost of traffic congestion on preterm births (\$444 million per year) estimated by Currie and Walker (2011).

A second benchmark broadens the scope to consider pollution more broadly, using the citywide estimates from Table 2. In the IV regressions, we estimate that a 1 standard deviation decrease in $\mathrm{PM}_{10}$ pollution is associated with a 2.9 percent reduction in violent crime. Between 2001 and 2012, average $\mathrm{PM}_{10}$ levels across all monitors in the Chicago metro area fell from roughly $28 \mu \mathrm{g} / \mathrm{m}^{3}$ to $18 \mu \mathrm{g} / \mathrm{m}^{3} .11$ Relative to the variation used to estimate the city-level regressions, this reflects a 0.69 standard deviation decrease in average $\mathrm{PM}_{10}$ levels citywide. Taken at face value, this would translate to a 2 percent reduction in violent crime using the IV estimates from Table 2. Obviously, a shortcoming of this calculation (and a limitation of the citywide estimates that we acknowledge) is that air pollution (across a wide range of pollutants) is declining over the study period and this back-of-the-envelope calculation treats $\mathrm{PM}_{10}$ emissions as a proxy for all pollutants. But, over the study period, 2001 to 2012, levels of $\mathrm{PM}_{10}$ and other pollutants declined by similar magnitudes. Average $\mathrm{NO}_{x}, \mathrm{PM}_{2.5}$, and $\mathrm{PM}_{10}$ readings in the Chicago area fell 35, 30, and 36 percent from 2001 to 2012, respectively. On base of roughly 46 thousand violent crimes in Chicago in 2001, a 2 percent reduction violent crimes would correspond to 920 fewer violent crimes. ${ }^{42}$ Assuming that these crimes were entirely the least costly violent crime (assaults), the crime reduction benefits for Chicago from pollution reduction over 2001-2012 might be conservatively estimated at \$22 million per

\footnotetext{
${ }^{39}$ Details of the calculation are in online Appendix Section III.

${ }^{40}$ In terms of a planner interested in aggregate crime, the question of spatial displacement — criminal behavior being shifted from one neighborhood to another-is an important one. While our interstate analysis does not allow us to tackle this directly, it is worth recalling that the city-level analysis supported the existence of a net effect of pollution. It is also the case that the interstates themselves offer a substantial barrier to mobility between neighborhoods that are adjacent but on alternative sides, potentially mitigating this concern given our approach to identification.

${ }^{41} \mathrm{~A}$ host of policies at the local, state, and federal levels contribute to this reduction. For mobile sources, the Chicago metro area began to require smog checks in the late 1990s, which, combined with the gradual retirement of vehicles lacking catalytic converters, reduced pollution from mobile sources. Similar emissions reductions occurred from industrial point sources, with the introduction and increased stringency of the US Acid Rain program (targeting sulfur dioxide) and NoX budget program.

${ }^{42}$ As a point of comparison, rates of violent crime in Chicago fell by roughly 40 percent over this period.
} 
annum. Scaling up to the urban population of the United States, the estimate would rise to $\$ 2.2$ billion per annum.

We do not take a stand on the exact underlying mechanism, but our results suggest that air pollution may impact behavior in economically meaningful ways much more broadly than previously considered. Although we focus on violent criminal activity as an outcome, the potential underlying loss of control and increased impulsivity may be related to other economically important decisions. These results also provide insight into potential behavioral explanations behind lost productivity and performance found by previous studies. Finally, we see our results as complementary to the literature on the cognitive effects of poverty (see, e.g., Mani et al. 2013; Schilbach, Schofield, and Mullainanathan 2016), in which cognitive load and stress lead to poor decision-making. Pollution exposure may have similar effects, which adds an additional dimension of concern to policy debates about environmental justice, disproportional pollution burdens among demographic groups within the United States, and high levels of pollution in the developing world.

\section{Conclusion}

The primary contribution of this paper is to identify a causal link from short-run variation in air pollution to violent crime. Our approach exploits variation in air quality induced by naturally occurring changes in wind direction in the city of Chicago. At the aggregate city level, we exploit wind-driven pollution shocks from industrial facilities to the southeast and southwest of the metro area and estimate that a 1 standard deviation decrease in $\mathrm{PM}_{10}$ pollution is associated with a 2.9 percent reduction in violent crime.

We complement the citywide evidence with evidence that exploits the microgeography of pollution and crime within Chicago. We study days during which the wind blows orthogonally to a major interstate such as the I-290 and use the upwind side of the interstate as a control for the treated downwind side. We find estimates broadly similar to the aggregate data (and to more recent papers studying pollution and crime). As in the city-level evidence, we find an increase in violent crime (but not property crime) on the downwind side of the interstate. Consistent with literature from medicine and psychology on a short-term impact of pollution on aggression, we find that contemporaneous, rather than lagged, exposure is most relevant. Furthermore, we find that as we alter the rules for constructing the study sample, the estimated magnitude of the treatment effect changes, as we would expect if air pollution were the driving mechanism.

In Chicago, violent crime increases by 1.9 percent in a neighborhood on the downwind side of a major interstate. Back-of-the-envelope calculations based on these magnitudes suggest that the cost to society is meaningful compared to other outcomes studied in the external costs literature.

Our work contributes to the growing recognition that in addition to the well-understood health benefits, air pollution may impact behavior and cognition in broader ways than previously considered. From a policy standpoint, the analysis suggests additional social cost of air pollution and that estimates of the marginal social cost may be greater that previously considered. 


\section{REFERENCES}

Allen, Ryan W., Hugh Davies, Martin A. Cohen, Gary Mallach, Joel D. Kaufman, and Sara D. Adar. 2009. "The Spatial Relationship between Traffic-Generated Air Pollution and Noise in 2 US Cities." Environmental Research 109 (3): 334-42.

-Amitai, Yona, Zoli Zlotogorski, Vered Golan-Katzav, Anya Wexler, and Ditza Gross. 1998. "Neuropsychological Impairment from Acute Low-Level Exposure to Carbon Monoxide." Archives of Neurology 55 (6): 845-48.

Anderson, Craig A., and Brad J. Bushman. 2002. "Human Aggression." Annual Review of Psychology 53: 27-51.

Anderson, David A. 1999. "The Aggregate Burden of Crime.” Journal of Law and Economics 42 (2): 611-42.

Anderson, Michael L. 2020. "As the Wind Blows: The Effects of Long-Term Exposure to Air Pollution on Mortality." Journal of the European Economic Association 18 (4): 1886-1927.

Archsmith, James, Anthony Heyes, and Soodeh Saberian. 2018. “Air Quality and Error Quantity: Pollution and Performance in a High-Skilled, Quality-Focused Occupation." Journal of the Association of Environmental and Resource Economists 5 (4): 827-63.

Baron, Robert A., and Paul A. Bell. 1976. "Aggression and Heat: The Influence of Ambient Temperature, Negative Affect, and a Cooling Drink on Physical Aggression." Journal of Personality and Social Psychology 33 (3): 245-55.

-Barrios, Thomas, Rebecca Diamond, Guido W. Imbens, and Michal Kolesár. 2012. "Clustering, Spatial Correlations, and Randomization Inference." Journal of the American Statistical Association 107 (498): 578-91.

Beatty, Timothy K.M., and Jay P. Shimshack. 2014. "Air Pollution and Children's Respiratory Health: A Cohort Analysis.” Journal of Environmental Economics and Management 67 (1): 39-57.

Birger, Moshe, Marnina Swartz, David Cohen, Ya'akov Alesh, Chaim Grishpan, and Moshe Kotelr. 2003. "Aggression: The Testosterone-Serotonin Link." Journal of Israel Medical Association 5 (9): 653-58.

Bondy, Malvina, Sefi Roth, and Lutz Sager. 2018. "Crime Is in the Air: The Contemporaneous Relationship between Air Pollution and Crime.” IZA Discussion Paper 11492.

Briere, John, Anthony Downes, and James Spensley. 1983. "Summer in the City: Urban Weather Conditions and Psychiatric Emergency-Room Visits." Journal of Abnormal Psychology 92 (1): 77-80.

-Burke, Marshall B., Edward Miguel, Shanker Satyanath, John A. Dykema, and David B. Lobell. 2009. "Warming Increases the Risk of Civil War in Africa." Proceedings of the National Academy of Sciences 106 (49): 20670-74.

Burkhardt, Jesse, Jude Bayham, Ander Wilson, Ellison Carter, Jesse D. Berman, Katelyn O'Dell, Bonne Ford, Emily V. Fischer, and Jeffrey R. Pierce. 2019. "The Effect of Pollution on Crime: Evidence from Data on Particulate Matter and Ozone.' Journal of Environmental Economics and Management 98: 102267.

Chang, Tom Y., Joshua Graff Zivin, Tal Gross, and Matthew Neidell. 2019. "The Effect of Pollution on Worker Productivity: Evidence from Call Center Workers in China.” American Economic Journal: Applied Economics 11 (1): 151-72.

Chicago Police Department (CPD). 2001-2012. "Citizen Law Enforcement Analysis and Reporting system." Chicago Data Portal. https://data.cityofchicago.org/Public-Safety/Crimes-2001-topresent-Dashboard/5cd6-ry5g (accessed February 4, 2013).

Coccaro, Emil F., Chandra Sekhar Sripada, Rachel N. Yanowitch, and K. Luan Phan. 2011. "Corticolimbic Function in Impulsive Aggressive Behavior.” Biological Psychiatry 69 (12): 1153-59.

Cohn, Ellen G., and James Rotton. 1997. "Assault as a Function of Time and Temperature: A Moderator-Variable Time-Series Analysis.” Journal of Personality and Social Psychology 72 (6): 1322-34.

Crockett, Molly J., Annemieke Apergis-Schoute, Benedikt Herrmann, Matthew D. Lieberman, Ulrich Müller, Trevor W. Robbins, and Luke Clark. 2013. "Serotonin Modulates Striatal Responses to Fairness and Retaliation in Humans." Journal of Neuroscience 33 (8): 3505-13.

-Currie, Janet, and Reed Walker. 2011. "Traffic Congestion and Infant Health: Evidence from E-ZPass." American Economic Journal: Applied Economics 3 (1): 65-90.

Dabbs, James M., Jr., Timothy S. Carr, Robert L. Frady, and Jasmin K. Riad. 1995. "Testosterone, Crime, and Misbehavior among 692 Male Prison Inmates." Personality and Individual Differences 18 (5): 627-33.

Doleac, Jennifer L., and Nicholas J. Sanders. 2015. "Under the Cover of Darkness: How Ambient Light Influences Criminal Activity.” Review of Economics and Statistics 97 (5): 1093-1103. 
-Faustman, William O., David L. Ringo, and Kym F. Faull. 1993. "An Association between Low Levels of 5-HIAA and HVA in Cerebrospinal Fluid and Early Mortality in a Diagnostically Mixed Psychiatric Sample.” British Journal of Psychiatry 163 (4): 519-21.

-Frankle, W. Gordon, Ilise Lombardo, Antonia S. New, Marianne Goodman, Peter S. Talbot, Yiyun Huang, Dah-Ren Hwang, et al. 2005. "Brain Serotonin Transporter Distribution in Subjects with Impulsive Aggressivity: A Positron Emission Study with [11C] McN 5652." American Journal of Psychiatry 162 (5): 915-23.

-González-Guevara, Edith, Juan Carlos Martínez-Lazcano, Verónica Custodio, Miguel Hernández-Cerón, Carmen Rubio, and Carlos Paz. 2014. "Exposure to Ozone Induces a Systemic Inflammatory Response: Possible Source of the Neurological Alterations Induced by This Gas." Inhalation Toxicology 26 (8): 485-91.

-Hanna, Rema, and Paulina Oliva. 2015. "The Effect of Pollution on Labor Supply: Evidence from a Natural Experiment in Mexico City." Journal of Public Economics 122: 68-79.

-Hansenne, Michel, Jean Reggers, Emmanuel Pinto, Karim Kjiri, Amar Ajamier, and Marc Ansseau. 1999. "Temperament and Character Inventory (TCI) and Depression." Journal of Psychiatric Research 33 (1): 31-36.

Hener, Timo. 2019. "Noise Pollution and Violent Crime." Paper presented at the Conference of the European Association of Environmental and Resource Economists, Manchester, UK, June 27.

Herrnstadt, Evan, Anthony Heyes, Erich Muehlegger, and Soodeh Saberian. 2021. "Replication data for: Air Pollution and Criminal Activity: Microgeographic Evidence from Chicago." American Economic Association [publisher], Inter-university Consortium for Political and Social Research [distributor]. https://doi.org/10.38886/E119403V1.

Hsiang, Solomon M., Marshall Burke, and Edward Miguel. 2013. "Quantifying the Influence of Climate on Human Conflict." Science 341 (6151): 1212.

-Hsiang, Solomon M., Kyle C. Meng, and Mark A. Cane. 2011. "Civil Conflicts Are Associated with the Global Climate." Nature 476 (7361): 438-41.

Ito, Koichiro, and Shuang Zhang. 2016. "Willingness to Pay for Clean Air: Evidence from Air Purifier Markets in China." NBER Working Paper 22367.

Iyer, Lakshmi, and Petia Topalova. 2014. "Poverty and Crime: Evidence from Rainfall and Trade Shocks in India." Harvard Business School BGIE Unit Working Paper 14-067.

Jacob, Brian, Lars Lefgren, and Enrico Moretti. 2007. "The Dynamics of Criminal Behavior Evidence from Weather Shocks." Journal of Human Resources 42 (3): 489-527.

-Karner, Alex A., Douglas S. Eisinger, and Deb A. Niemeier. 2010. "Near-Roadway Air Quality: Synthesizing the Findings from Real-World Data." Environmental Science and Technology 44 (14): 5334-44.

Krueger, Albert P., Paul C. Andriese, and Sadao Kotaka. 1963. "The Biological Mechanism of Air Ion Action: The Effect of $\mathrm{CO} 2+$ in Inhaled Air on the Blood Level of 5-Hydroxytryptamine in Mice." International Journal of Biometeorology 7 (1): 3-16.

Lavy, Victor, Avraham Ebenstein, and Sefi Roth. 2014. "The Impact of Short Term Exposure to Ambient Air Pollution on Cognitive Performance and Human Capital Formation." NBER Working Paper 20648.

Levesque, Shannon, Thomas Taetzsch, Melinda E. Lull, Urmila Kodavanti, Krisztian Stadler, Alison Wagner, Jo Anne Johnson, et al. 2011. "Diesel Exhaust Activates \& Primes Microglia: Air Pollution, Neuroinflammation, \& Regulation of Dopaminergic Neurotoxicity." Environmental Health Perspectives 119 (8): 1149-55.

- Lim, Youn-Hee, Ho Kim, Jin Hee Kim, Sanghyuk Bae, Hye Yin Park, and Yun-Chul Hong. 2012. "Air Pollution and Symptoms of Depression in Elderly Adults." Environmental Health Perspectives 120 (7): 1023-28.

Lu, Jackson G., Julia J. Lee, Francesca Gino, and Adam D. Galinsky. 2018. "Polluted Morality: Air Pollution Predicts Criminal Activity and Unethical Behavior." Psychological Science 29 (3): 340-55.

- Maney, Donna L., and James L. Goodson. 2011. "Neurogenomic Mechanisms of Aggression in Songbirds." Advances in Genetics 75: 83-119.

-Mani, Anandi, Sendhil Mullainanathan, Eldar Shafir, and Jiaying Zhao. 2013. "Poverty Impedes Cognitive Function." Science 341 (6149): 976-80.

Moretti, Enrico, and Matthew Neidell. 2011. "Pollution, Health, and Avoidance Behavior Evidence from the Ports of Los Angeles." Journal of Human Resources 46 (1): 154-75.

- Murphy, Shannon R., Edward S. Schelegle, Lisa A. Miller, Dallas M. Hyde, and Laura S. Van Winkle. 2013. "Ozone Exposure Alters Serotonin and Serotonin Receptor Expression in the Developing Lung.” Toxicological Sciences 134 (1): 168-79. 
National Climate Data Center (NCDC). 2001-2012. "Integrated Surface Database.” National Oceanic and Atmospheric Administration. ftp://ftp.ncdc.noaa.gov/pub/data/noaa/ (accessed February 28, 2013).

-Nattero, Giovanni, and Annalisa Enrico. 1996. "Outdoor Pollution and Headache." Headache 36 (4): $243-45$

- Paz, Carlos, and Salvador Huitrón-Reséndiz. 1996. "The Effects of Ozone Exposure on the SleepWake Cycle and Serotonin Contents in the Pons of the Rat." Neuroscience Letters 204 (1-2): 49-52.

- Rammal, Hassan, Jaouad Bouayed, Chafique Younos, and Rachid Soulimani. 2008. "Evidence that Oxidative Stress Is Linked to Anxiety-Related Behaviour in Mice." Brain, Behavior, and Immunity 22 (8): 1156-59.

-Ranson, Matthew. 2014. "Crime, Weather, and Climate Change." Journal of Environmental Economics and Management 67 (3): 274-302.

Reyes, Jessica Wolpaw. 2007. "Environmental Policy as Social Policy? The Impact of Childhood Lead Exposure on Crime." B.E. Journal of Economic Analysis and Policy 7 (1): Article 51.

Rotton, James. 1983. "Affective and Cognitive Consequences of Malodorous Pollution." Basic and Applied Social Psychology 4 (2): 171-91.

- Rotton, James, Timothy Barry, James Frey, and Edgardo Soler. 1978. "Air Pollution and Interpersonal Attraction." Journal of Applied Social Psychology 8 (1): 57-71.

Rotton, James, and James Frey. 1984. "Psychological Costs of Air Pollution: Atmospheric Conditions, Seasonal Trends, and Psychiatric Emergencies." Population and Environment 7 (1): 3-16.

-Rotton, James, and James Frey. 1985. "Air Pollution, Weather, and Violent Crimes: Concomitant Time-Series Analysis of Archival Data." Journal of Personality and Social Psychology 49 (5): 1207-20.

-Schilbach, Frank, Jennifer Schofield, and Sendhil Mullainanathan. 2016. "The Psychological Lives of the Poor." American Economic Review 106 (5): 435-40.

-Schlenker, Wolfram, and W. Reed Walker. 2016. "Airports, Air Pollution, and Contemporaneous Health.” Review of Economic Studies 83 (2): 768-809.

-Shu, Shi, Pu Yang, and Yifang Zhu. 2014. "Correlation of Noise Levels and Particulate Matter Concentrations near Two Major Freeways in Los Angeles, California." Environmental Pollution 193: 130-37.

-Siegel, Jenifer Z., and Molly J. Crockett. 2013. "How Serotonin Shapes Moral Judgment and Behavior." Annals of the New York Academy of Sciences 1299 (1): 42-51.

Stafford, Tess M. 2014. "Indoor Air Quality and Academic Performance." Journal of Environmental Economics and Management 70: 34-50.

-Strahilevitz, Meir, Aharona Strahilevitz, and John E. Miller. 1979. "Air Pollutants and the Admission Rate of Psychiatric Patients." American Journal of Psychiatry 136 (2): 205-07.

Szyszkowicz, Mieczysław. 2007. "Air Pollution and Emergency Department Visits for Depression in Edmonton, Canada." International Journal of Occupational Medicine and Environmental Health 20 (3): 241-45.

Szyszkowicz, Mieczysław, Jeff B. Willey, Eric Grafstein, Brian H. Rowe, and Ian Colman. 2010. "Air Pollution and Emergency Department Visits for Suicide Attempts in Vancouver, Canada." Environmental Health Insights 4: 79-86.

-Uboh, F.E., M.I. Akpanabiatu, I.S. Ekaidem, P.E. Ebong, and I.B. Umoh. 2007. "Effect of Inhalation Exposure to Gasoline on Sex Hormones Profile in Wistar Albino Rats." Acta Endocrinologica 3 (1): 23-30.

- Van Berlo, Damien, Catrin Albrecht, Ad M. Knaapen, Flemming R. Cassee, Miriam E. Gerlofs-Nijland, Ingeborg M. Kooter, Nicola Palomero-Gallagher, et al. 2010. "Comparative Evaluation of the Effects of Short-Term Inhalation Exposure to Diesel Engine Exhaust on Rat Lung and Brain." Archives of Toxicology 84 (7): 553-62.

-Weber, Stephan. 2009. "Spatio-temporal Covariation of Urban Particle Number Concentration and Ambient Noise." Atmospheric Environment 43 (34): 5518-25.

-Yang, Albert C., Shi-Jen Tsai, and Norden E. Huang. 2011. "Decomposing the Association of Completed Suicide with Air Pollution, Weather, and Unemployment Data at Different Time Scales." Journal of Affective Disorders 129 (1-3): 275-81.

Zivin, Joshua Graff, and Matthew Neidell. 2009. "Days of Haze: Environmental Information Disclosure and Intertemporal Avoidance Behavior." Journal of Environmental Economics and Management 58 (2): 119-28.

-Zivin, Joshua Graff, and Matthew Neidell. 2012. "The Impact of Pollution on Worker Productivity." American Economic Review 102 (7): 3652-73. 